\title{
Edoxaban: An Update on the New Oral Direct Factor Xa Inhibitor
}

\author{
Henri Bounameaux $\cdot$ A. John Camm
}

Published online: 18 July 2014

(c) The Author(s) 2014. This article is published with open access at Springerlink.com

\begin{abstract}
Edoxaban is a once-daily oral anticoagulant that rapidly and selectively inhibits factor $\mathrm{Xa}$ in a concentrationdependent manner. This review describes the extensive clinical development program of edoxaban, including phase III studies in patients with non-valvular atrial fibrillation (NVAF) and symptomatic venous thromboembolism (VTE). The ENGAGE AF-TIMI 48 study $(N=21,105$; mean $\mathrm{CHADS}_{2}$ score 2.8) compared edoxaban $60 \mathrm{mg}$ once daily (high-dose regimen) and edoxaban $30 \mathrm{mg}$ once daily (lowdose regimen) with dose-adjusted warfarin [international normalized ratio (INR) 2.0-3.0] and found that both regimens were non-inferior to warfarin in the prevention of stroke and systemic embolism in patients with NVAF. Both edoxaban regimens also provided significant reductions in the risk of hemorrhagic stroke, cardiovascular mortality, major bleeding and intracranial bleeding. The Hokusai-VTE study $(N=8,292)$ in patients with symptomatic VTE had a flexible treatment duration of 3-12 months and found that following initial heparin, edoxaban $60 \mathrm{mg}$ once daily was non-inferior to dose-adjusted warfarin (INR 2.0-3.0) for the prevention of recurrent VTE, and also had a significantly lower risk of
\end{abstract}

Electronic supplementary material The online version of this article (doi:10.1007/s40265-014-0261-1) contains supplementary material, which is available to authorized users.

\section{H. Bounameaux}

Department of Internal Medicine, University Hospital of Geneva, Geneva, Switzerland

H. Bounameaux $(\bowtie)$

Faculty of Medicine, Dean's Office, University Medical Center (CMU), Rue Michel Servet, 1, 1211 Geneva 4, Switzerland e-mail: henri.bounameaux@unige.ch

A. J. Camm

Division of Clinical Sciences, St George's University of London, London, UK bleeding events. Both studies randomized patients at moderate-to-high risk of thromboembolic events and were further designed to simulate routine clinical practice as much as possible, with edoxaban dose reduction (halving dose) at randomisation or during the study if required, a frequently monitored and well-controlled warfarin group, a well-monitored transition period at study end and a flexible treatment duration in Hokusai-VTE. Given the phase III results obtained, once-daily edoxaban may soon be a key addition to the range of antithrombotic treatment options.

\section{Key Points}

Pivotal phase III studies with edoxaban, a rapid, selective, once-daily, oral factor Xa inhibitor have recently been completed.

The ENGAGE AF-TIMI 48 study in patients with non-valvular atrial fibrillation at moderate-to-high risk of stroke $\left(N=21,105\right.$; mean $\mathrm{CHADS}_{2}$ score 2.8), found that both high-dose edoxaban $60 \mathrm{mg}$ once daily and low-dose edoxaban $30 \mathrm{mg}$ once daily were non-inferior to well-controlled warfarin in the prevention of stroke or systemic embolism, and were also associated with significantly less bleeding and death from a cardiovascular cause than warfarin.

The Hokusai-VTE study in patients with acute symptomatic venous thromboembolism (VTE) [ $N=8,292]$ had a flexible treatment duration of 3-12 months and found that initial heparin/edoxaban $60 \mathrm{mg}$ once daily was non-inferior to heparin/wellcontrolled warfarin for the treatment and prevention of recurrent VTE, with a significantly reduced risk of bleeding. 


\section{Introduction}

Oral anticoagulant therapy is the cornerstone of stroke prevention in patients with atrial fibrillation (AF) and, overlapped with parenteral heparin, for the treatment and prevention of venous thromboembolism (VTE). Oral anticoagulation with vitamin $\mathrm{K}$ antagonists (VKAs) such as warfarin has been used for several decades but has a number of limitations in long-term clinical use, including variability in dose response; frequent, complex dose adjustments; inadequate levels of anticoagulation; increased risk of major bleeding or intracranial hemorrhage, particularly in the elderly; drug and food interactions; a slow onset of action; a narrow therapeutic margin; high discontinuation rates; and the need for coagulation monitoring [1-3]. Obtaining the correct dose can often be difficult and delayed at the initiation of VKA treatment. Therefore pharmacogenetic studies recently assessed the utility of genotype testing in choosing an initial dose of VKA, showing that it offers only a limited to marginal improvement versus standard of care [4-6]. In clinical practice, it has been observed that between 40 and $50 \%$ of patients at risk do not receive treatment, in part because VKAs are inconvenient for patients and physicians are concerned about an increased bleeding risk [7-9].

The process of coagulation involves an amplifying cascade in which one molecule of factor Xa can generate approximately 1,000 molecules of thrombin [10]. Thus, non-VKA oral anticoagulants (NOACs) have been developed that selectively target factor Xa (apixaban, edoxaban, rivaroxaban and betrixaban) and also thrombin directly (dabigatran). After decades of only one treatment option, the NOACs have ushered in a new era in oral anticoagulation. Several countries have approved the use of NOACs for AF-related stroke prevention and for the prevention or treatment of VTE. Although limited postmarketing surveillance data were currently available, the 2012 European Society of Cardiology (ESC) and 2012 Canadian Cardiovascular Society (CCS) AF guideline updates both included a preference for NOACs in non-valvular AF (NVAF) patients at risk of thromboembolism [11, 12]. The 2014 update of the American Heart Association (AHA)/American College of Cardiology (ACC)/Heart Rhythm Society (HRS) AF guidelines recommended that in patients with NVAF and prior stroke, transient ischemic attack or a $\mathrm{CHA}_{2} \mathrm{DS}_{2}$-VASc score $\geq 2$, treatment with an oral anticoagulant such as warfarin [international normalized ratio (INR) 2.0-3.0], dabigatran, rivaroxaban or apixaban was recommended [13]. In patients who were not able to maintain therapeutic INR on warfarin treatment, the AHA/ ACC/HRS guidelines recommended switching to an NOAC [13]. In addition, the 2012 AHA/American Stroke Association (ASA) AF guidelines recommended that dabigatran, apixaban and rivaroxaban were suitable alternatives to warfarin in patients with NVAF, risk factors for stroke or systemic embolism and without severe renal impairment [14]. Regarding recommendations in patients with VTE, the 2012 American College of Chest Physicians (ACCP) VTE guidelines recommended initial treatment with a parenteral heparin or fondaparinux, overlapped with a VKA, dabigatran or rivaroxaban for anticoagulation treatment [15].

The benefits of NOAC treatment have recently been highlighted in meta-analyses of all four new oral agents tested in phase III trials for stroke prevention in AF and the treatment of acute VTE. In patients with $\mathrm{AF}(N=71,683)$, the NOACs reduced the risk of stroke or systemic embolic events (SEEs) by $19 \%$, major bleeding by $14 \%$ and intracranial hemorrhage by $52 \%$ compared with warfarin [16]. In patients with acute VTE $(N=24,455)$, the NOACs were non-inferior to VKAs in the treatment of VTE, and were also associated with a significantly lower risk of major bleeding than VKAs [17]. In addition to efficacy and safety benefits, the NOACs offer important practical advantages over VKA treatment, including a rapid onset of action, no significant food interactions, lower potential for drug interactions, and a predictable anticoagulant effect that obviates the need for routine coagulation monitoring [16].

The results of phase III clinical studies with edoxaban have recently been reported for stroke prevention in patients with $\mathrm{AF}$ and in the treatment of acute symptomatic VTE. The objective of this review was to discuss these findings and other key clinical and pharmacology studies with edoxaban, and provide a perspective for edoxaban in clinical practice.

\section{Pharmacokinetic Properties}

Clinical pharmacokinetic studies of edoxaban have shown it has a predictable and consistent pharmacokinetic profile (Table 1). In healthy subjects, edoxaban has predictable pharmacokinetics that are closely related to dose. It is rapidly absorbed and reaches peak plasma concentrations $\left(C_{\max }\right)$ in $1-2 \mathrm{~h}$, with peak anti-factor Xa activity achieved approximately $1.5 \mathrm{~h}$ after oral administration and remaining above baseline levels for up to $24 \mathrm{~h} \mathrm{[18-20].} \mathrm{Edoxaban}$ has a half-life of approximately 10-14 $\mathrm{h}$ and its absolute oral bioavailability is $62 \%$ in healthy subjects [21, 22, 23]. Plasma protein binding of edoxaban is approximately $55 \%$, which is lower than with apixaban $(87 \%)$ and rivaroxaban $(\sim 90 \%)$ (Table 1$)$. Its relatively low protein binding may be an important property of edoxaban because of implications for patients on hemodialysis treatment; hemodialysis did not affect protein binding, exposure or 


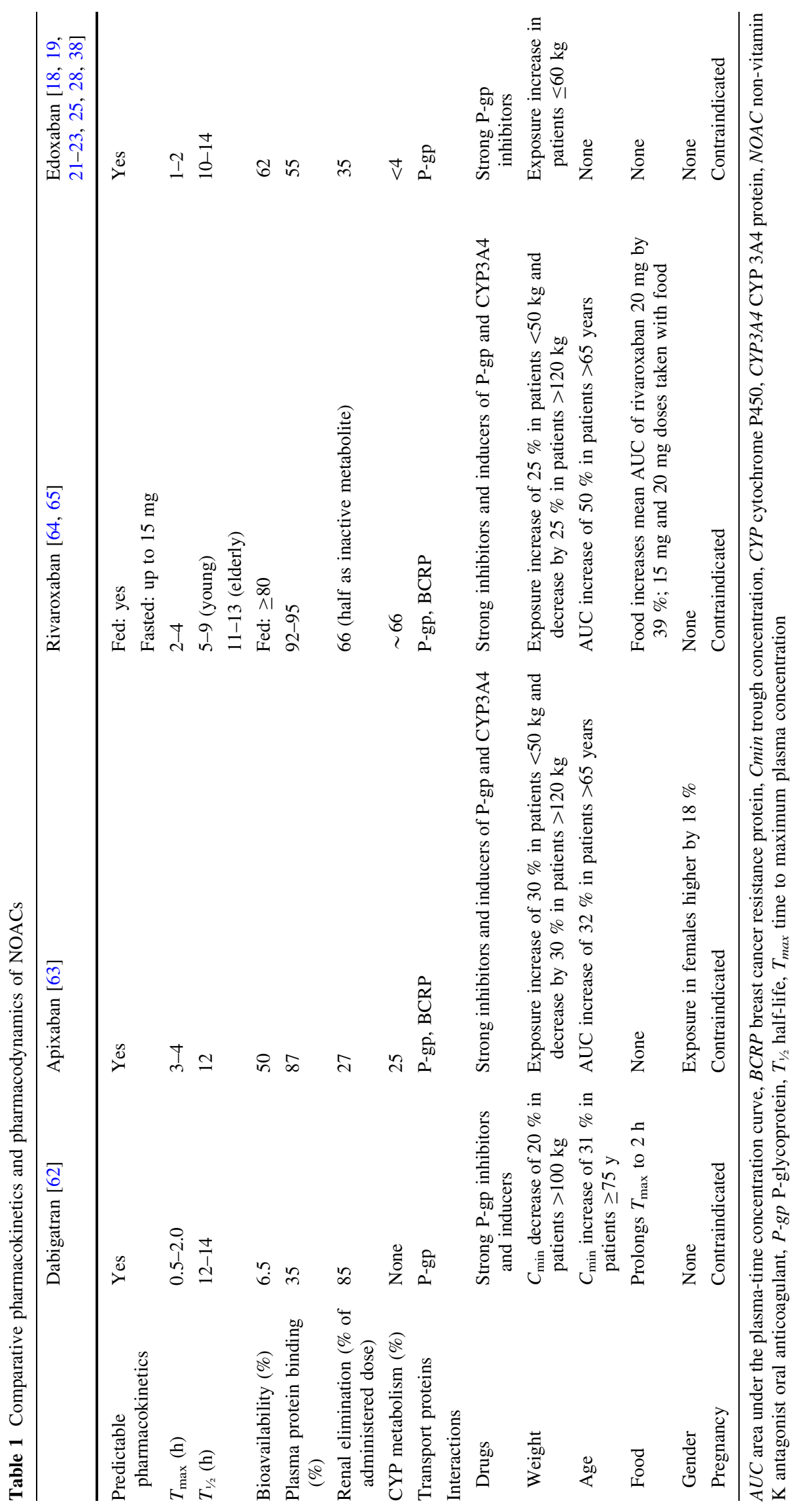


clearance of edoxaban (see Sect. 4.2.3) [24]. Food interactions with VKAs are a limitation in the daily lives of patients [1], but food intake, and also ethnicity and gender, have no influence on edoxaban absorption, elimination, $C_{\text {max }}$, half-life or anti-factor Xa activity $[25,26]$.

Edoxaban undergoes biotransformation to various metabolites and the most abundant of these (M4) is formed through hydrolysis [27, 28]. Although the majority of an edoxaban dose is excreted within $24 \mathrm{~h}$, over $70 \%$ is excreted unchanged [28]. Edoxaban is eliminated in faeces and urine, and a lower proportion of the administered dose of edoxaban is eliminated via the kidneys (35\%) than with dabigatran $(85 \%)$ and rivaroxaban $(66 \%)$ (Table 1) [2, 28].

Edoxaban $60 \mathrm{mg}$ has also been assessed by Zahir et al. during and $12 \mathrm{~h}$ after enoxaparin $1 \mathrm{mg} / \mathrm{kg}$ administration in healthy volunteers $(N=40)$ [20]. This study found that the pharmacokinetics of edoxaban [area under the plasmaconcentration curve (AUC); $C_{\max }$ ] were not affected by enoxaparin, whether administered concomitantly or $12 \mathrm{~h}$ apart. Edoxaban administered $12 \mathrm{~h}$ post-enoxaparin had comparable or less inhibitory effects on thrombin generation compared with concomitant enoxaparin administration, but greater inhibitory effects compared with edoxaban alone. There were no serious adverse events during the study and edoxaban was well tolerated when administered $12 \mathrm{~h}$ post-enoxaparin [20].

A very limited proportion of edoxaban $(<4 \%)$ is metabolized by cytochrome $\mathrm{P} 450$ and intestinal transport of edoxaban, as with other NOACs, occurs through the P-glycoprotein (P-gp) efflux transporter mechanism [28, 29]. The potential interaction between P-gp inhibitors and edoxaban has therefore been characterized. The P-gp inhibitor quinidine increases edoxaban exposure by $76.7 \%$, verapamil by $52.7 \%$ and dronedarone by $84.5 \%$, which are all over 1.5-fold, and therefore the dose of edoxaban was reduced with concomitant treatment [22]. Amiodarone increases edoxaban exposure by $39.8 \%$ and therefore can be administered concomitantly without edoxaban dose reduction [22]. Certain macrolide antibiotics (erythromycin, azithromycin and clarithromycin), azole antifungals (ketoconazole and itraconazole) and strong P-gp inhibitors (ritonavir and cyclosporine) increase edoxaban steady-state plasma concentrations, and it has been recommended that systemic concomitant treatment with edoxaban is contraindicated, which was outlined in the ENGAGE AF-TIMI 48 study protocol [30]. Similarly, a significant increase in rivaroxaban exposure has been observed during concomitant treatment with ketoconazole and ritonavir [31].

Concomitant therapy with aspirin has also been studied with edoxaban, and it was found that a high-dose of aspirin $325 \mathrm{mg} /$ day increased edoxaban exposure by $30 \%$ and
$C_{\max }$ by $34 \%$, whereas concomitant aspirin $100 \mathrm{mg} /$ day did not influence edoxaban pharmacokinetics [32]. Thus, in phase III clinical trials with edoxaban, concomitant aspirin was limited to doses $\leq 100 \mathrm{mg} /$ day $[30,33]$.

\section{Pharmacodynamic Properties}

A phase I clinical study by Zafar et al. showed that edoxaban causes substantial changes in INR, prothrombin time (PT), anti-factor Xa activity and activated partial thromboplastin time (aPTT). In particular, edoxaban prolonged aPTT by 1.3 -fold, PT by 2.0 -fold and INR by 2.0 fold, all in a concentration-dependent manner [18]. In addition, edoxaban $60 \mathrm{mg}$ inhibits thrombin generation for up to $24 \mathrm{~h}$ [20].

In an ex vivo study in healthy volunteers $(N=12)$, the antithrombotic effects of edoxaban $60 \mathrm{mg}$ once daily were assessed under both venous and arterial flow conditions [18]. This study found that under venous flow conditions after 1.5 and $5 \mathrm{~h}$, the thrombus was 28 and $21 \%$ smaller versus baseline, respectively $(p<0.05)$. Similarly, under arterial conditions, the corresponding reductions in thrombus size were 26 and $17 \%(p<0.05)$. Thrombin generation also decreased by $28 \%$ at $1.5 \mathrm{~h}$ and $10 \%$ at $5 \mathrm{~h}$, and was also associated with a decrease in size of the acute platelet-rich thrombus [18]. Of note was that changes in clotting parameters PT, INR and anti-factor Xa activity correlated very closely with plasma edoxaban concentrations $\left(R^{2}=0.79,0.78\right.$ and 0.85 , respectively) [18].

Also of interest is a study of edoxaban administered $24 \mathrm{~h}$ post warfarin therapy in healthy volunteers, which found edoxaban was well tolerated, and transient increases in PT, aPTT and anti-factor Xa activity returned to baseline levels $24 \mathrm{~h}$ after edoxaban dosing [34]. In addition, a single supratherapeutic dose of edoxaban 90 or $180 \mathrm{mg}$ had no effect on corrected QT interval versus placebo in healthy volunteers, which suggested there is a low potential for edoxaban to induce cardiac arrhythmias at therapeutic doses (60 or $30 \mathrm{mg}$ once daily) [35].

\section{Clinical Trials}

\subsection{Phase I Clinical Trials}

A dose-ranging study of edoxaban by Ogata et al. in healthy volunteers assessed the safety of single doses of edoxaban $10-150 \mathrm{mg}$ once daily and multiple dosing of edoxaban 90 and $120 \mathrm{mg}$ once daily and edoxaban $60 \mathrm{mg}$ twice daily. All edoxaban doses were well tolerated and no dose-dependent increase in treatment-emergent adverse events (TEAEs) was observed [19]. After single doses of 
edoxaban, TEAEs were reported in $17.4 \%$ of subjects compared with $9.5 \%$ in the placebo group. No serious adverse events were observed and $76.7 \%$ of TEAEs were mild. Similarly, after multiple administration of edoxaban, $77.0 \%$ of TEAEs were mild and no serious adverse events were reported [19]. The effects of edoxaban on clotting parameters in healthy volunteers closely resembled those determined ex vivo. Edoxaban plasma concentrations correlated with PT and aPTT after single administration $\left(R^{2}=0.94\right.$ and 0.90 , respectively) and multiple administration $\left(R^{2}=0.97\right.$ and 0.89 , respectively). Edoxaban had dose-dependent effects on INR that reached a maximum value of 3.5 and were reversible within 24-36 h [19].

\subsection{Phase II Clinical Trials}

\subsubsection{Stroke Prevention in Atrial Fibrillation (AF)}

The edoxaban phase II dose-ranging program in $\mathrm{AF}$ patients was the most extensive performed among the NOACs. A 12-week, parallel-group, multinational, doseranging study by Weitz et al. in AF patients at risk of stroke $(N=1,146)$, randomized patients to double-blind edoxaban $30 \mathrm{mg}$ once daily, $60 \mathrm{mg}$ once daily, $30 \mathrm{mg}$ twice daily, $60 \mathrm{mg}$ twice daily and open-label, dose-adjusted warfarin (INR 2.0-3.0) [36]. The incidence of major and clinically relevant non-major (CRNM) bleeding was significantly higher in the twice-daily edoxaban $60 \mathrm{mg}$ $(10.6 \% ; p=0.002)$ and $30 \mathrm{mg}(7.8 \% ; p=0.029)$ groups, compared with the warfarin group $(3.2 \%)$ (Fig. 1). However, there was no significant difference in major or CRNM bleeding between the warfarin and once-daily edoxaban 60 and $30 \mathrm{mg}$ groups [36]. Furthermore, trough edoxaban concentrations $\left(C_{\mathrm{min}}\right)$ were more closely linked to bleeding rates than $C_{\max }$ (Fig. 1). The higher edoxaban trough concentrations seen with twice-daily versus oncedaily dosing may explain the higher bleeding incidence with twice-daily dosing [36].

A similar 12-week, parallel-group, multinational, doseranging study by Yamashita et al. in Asian patients with $\mathrm{AF}$ $(N=536)$ randomized patients to double-blind edoxaban $30 \mathrm{mg}, 45 \mathrm{mg}$, and $60 \mathrm{mg}$ once daily and open-label, doseadjusted warfarin (INR 2.0-3.0) [37]. This study found edoxaban 30,45 and $60 \mathrm{mg}$ once daily were associated with comparable rates of all bleeding, major bleeding, and major and CRNM bleeding compared with warfarin, and there were no statistically significant differences between groups. In addition, the $C_{\min }$ of edoxaban was linked to
Fig. 1 a Edoxaban plasma exposure by dosing regimen; b incidence of major and CRNM bleeding events by edoxaban dose group. AUC area under the plasma concentrationtime curve, $B I D$ twice daily, $C_{\text {maxss }}$ peak steady-state plasma concentration, $C_{\text {minss }}$ trough steady-state plasma concentration, CRNM clinically relevant non-major, $N S$ nonsignificant, $Q D$ once daily. Reproduced from Weitz et al. [36], with permission
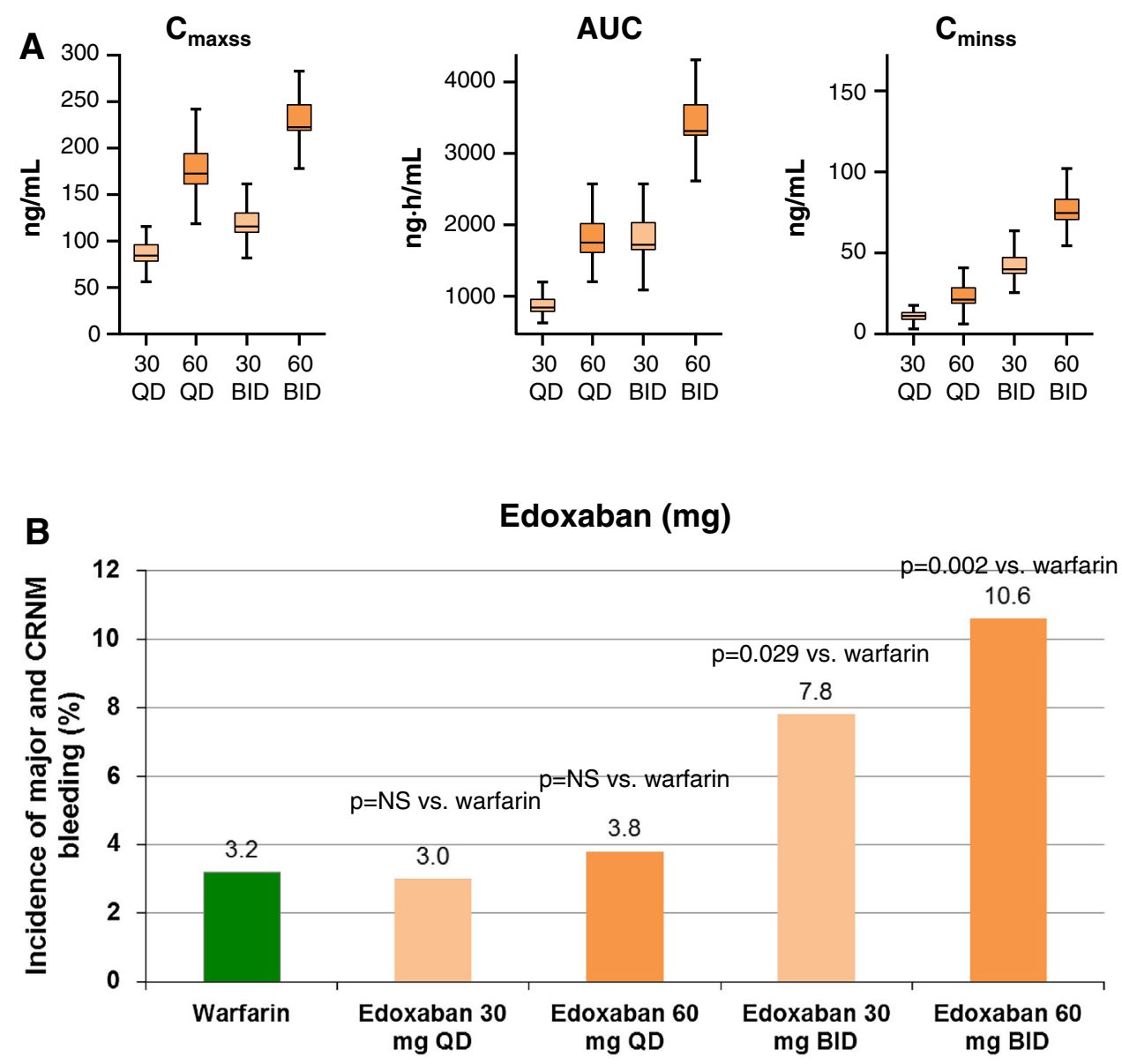
edoxaban dose and was higher in patients with body weight $\leq 60 \mathrm{~kg}$ than in those $>60 \mathrm{~kg}$. The incidence of bleeding events was also higher in patients who were $\leq 60 \mathrm{~kg}$ than $>60 \mathrm{~kg}$ in every treatment group and the difference was most pronounced in the edoxaban $60 \mathrm{mg}$ group, increasing from $22.0 \%$ (>60 kg subgroup) to $41.0 \%$ ( $\leq 60 \mathrm{~kg}$ subgroup) [37]. In addition, a further study by Chung et al. in Asian patients with $\mathrm{AF}(N=235)$ compared double-blind edoxaban $30 \mathrm{mg}$ and $60 \mathrm{mg}$ once daily with dose-adjusted warfarin (INR 2.0-3.0) [38]. Edoxaban $60 \mathrm{mg}$ and $30 \mathrm{mg}$ once daily were both associated with similar frequencies of all bleeding, major bleeding and minor bleeding events, which were all lower than with warfarin treatment. Moreover, in both the edoxaban $60 \mathrm{mg}$ and $30 \mathrm{mg}$ groups, the incidence of all bleeding events in the subgroup of patients with body weight $\leq 60 \mathrm{~kg}$ was higher than that in the subgroup of those who weighed $>60 \mathrm{~kg}$ [38]. Furthermore, two open-label, dose-escalation studies performed in warfarin-naïve Japanese patients with AF, who were titrated from edoxaban 5-30 mg (low-dose study, $N=24$ ) and from edoxaban 30-60 mg (high-dose study, $N=32$ ), confirmed the linear relationship between plasma edoxaban concentrations, pharmacodynamic variables and reductions in key coagulation biomarkers (D-dimer, thrombin-antithrombin and prothrombin fragment $F_{1+2}$ ) [39].

Prior to initiation of the phase III study in patients with $\mathrm{AF}$, a pooled analysis of phase I and phase II AF study results assessed the population pharmacokinetics of edoxaban, in order to identify factors that may affect exposure, biomarkers that influence bleeding risk and aid dose selection in the phase III study [40]. The data set included a total of 15 clinical studies of 1,281 subjects comprising 494 healthy subjects and 787 patients with AF. The modeling analyses found a statistically significant effect of patient creatinine clearance on apparent edoxaban systemic clearance $(\mathrm{CL} / \mathrm{F})$, and this was the most significant factor to influence edoxaban disposition. Body weight and AF status were found to have significant effects on apparent volume of the central compartment $(\mathrm{Vc} / \mathrm{F})$. In addition, concomitant P-gp inhibitor treatment had significant effects on $\mathrm{CL} / \mathrm{F}$ and edoxaban absorption rate constant $(\mathrm{Ka})$, and appeared to increase edoxaban relative bioavailability $\left(\mathrm{F}_{\text {rel }}\right)$. Modeling of edoxaban exposure in patients with moderate renal impairment receiving strong $\mathrm{P}$-gp inhibitors found they could potentially increase the steady-state AUC $\left(\mathrm{AUC}_{\mathrm{ss}}\right)$ and $C_{\mathrm{min}}\left(C_{\mathrm{min}, \mathrm{ss}}\right)$ up to threefold, compared with patients with normal renal function not taking strong $\mathrm{P}$-gp inhibitors. On the basis of similar and lower rates of bleeding compared with warfarin, edoxaban $60 \mathrm{mg}$ and $30 \mathrm{mg}$ once daily, respectively, were recommended for assessment in the phase III ENGAGE AF-TIMI 48 study in patients with NVAF (electronic supplementary Fig. 1) [41]. Taken together, this analysis and observations in the phase II studies suggested that edoxaban dose reduction (halving dose) be performed in patients taking a strong P-gp inhibitor, patients with moderate renal impairment (creatinine clearance $30-50 \mathrm{~mL} / \mathrm{min}$ ) or in patients with body weight $\leq 60 \mathrm{~kg}[37,38,40]$.

\subsubsection{Prevention of Venous Thromboembolism (VTE) After Orthopedic Surgery}

It is recommended that patients undergoing total hip or knee arthroplasty surgery receive a minimum of 10-14 days of antithrombotic therapy because they are at high risk of postoperative VTE. Treatment can reduce the risk of deep-vein thrombosis (DVT) by 50-60\% and pulmonary embolism (PE) by up to $66 \%$ [42].

Edoxaban was investigated in a dose-ranging study by Raskob et al. for the prevention of VTE in patients undergoing elective hip replacement surgery $(N=903)$ in the US [43]. This active-controlled study randomized patients to edoxaban $15,30,60$ or $90 \mathrm{mg}$ once daily or dalteparin once daily (initial dose 2,500 IU, followed by $5,000 \mathrm{IU})$, beginning 6-8 h postoperatively and continuing for 7-10 days. The incidence of VTE was 28.2, 21.2, 15.2 and $10.6 \%$ in patients receiving edoxaban 15, 30, 60 and $90 \mathrm{mg}$, respectively, compared with a significantly higher rate of $43.8 \%$ in the dalteparin group $(p<0.005)$. In addition, there was a statistically significant dose-response for efficacy across the edoxaban dose groups for total and major VTE $(p<0.001)$ and comparable rates of clinically relevant bleeding in all edoxaban and dalteparin groups [43]. In addition, edoxaban $15 \mathrm{mg}$ and $30 \mathrm{mg}$ once daily have been compared with subcutaneous enoxaparin for VTE prevention, in a similar phase IIb, randomized, parallel-group study of Japanese patients undergoing total hip replacement surgery $(N=264)$ [44]. Treatment was administered for 11-14 days after surgery and this study found no difference in the incidence of thromboembolic events, which were $3.8,2.8$ and $4.1 \%$ in the edoxaban 15 and $30 \mathrm{mg}$ and enoxaparin groups, respectively. There was also no difference in major or CRNM bleeding between the treatment groups [44].

With regard to the prevention of VTE following total knee replacement surgery, a phase IIb, dose-ranging, randomized, placebo-controlled study in Japanese patients $(N=523)$ compared edoxaban 5, 15, 30 and $60 \mathrm{mg}$ once daily with placebo for 11-14 days after surgery [45]. This study did not use low-molecular weight heparin or fondaparinux as a control treatment because they were not approved in Japan at the time of study initiation. Edoxaban treatment resulted in a dose-dependent and significant reduction in VTE incidences, which were 29.5, 26.1, 12.5 and $9.1 \%$ in the edoxaban 5, 15, 30 and $60 \mathrm{mg}$ groups, respectively, compared with $48.3 \%$ in the placebo group 
( $p<0.001$ for all edoxaban doses vs. placebo). There was also no significant difference in major bleeding or major or CRNM bleeding rates between any of the edoxaban dose groups and placebo [45].

The phase II studies of edoxaban for the prevention of VTE following total hip or knee replacement surgery found that edoxaban is effective in preventing VTE and is well tolerated, with a bleeding incidence similar to placebo after knee replacement surgery and also to enoxaparin or dalteparin after hip replacement surgery [43-45]. Subsequent Japanese phase III studies for the prevention of VTE following orthopedic surgery assessed the edoxaban $30 \mathrm{mg}$ once-daily dose on the basis of the efficacy, safety and bleeding findings in the phase II study program.

\subsubsection{Patients with Renal Impairment}

In view of the role of the kidneys in the elimination of edoxaban, Koretsune et al. performed an open-label, 8 -week study in patients with $\mathrm{AF}$ and renal impairment $(N=93)$ [46]. They compared edoxaban $15 \mathrm{mg}$ once daily in patients with severe renal impairment with edoxaban $60 \mathrm{mg}$ and $30 \mathrm{mg}$ once daily in patients with normal renal function or mild renal impairment. Bleeding events occurred at a similar rate in each group and no major bleeding events were seen in any group. Median PT ratios were also similar in the edoxaban $15 \mathrm{mg}$ (severe renal impairment) and $30 \mathrm{mg}$ (normal renal function or mild impairment) groups for up to $8 \mathrm{~h}$ after drug administration. Therefore, this preliminary study suggests that edoxaban $15 \mathrm{mg}$ once daily may be an appropriate dose in patients with $\mathrm{AF}$ and severe renal impairment [46].

A similar open-label study was conducted in Japanese patients with renal impairment $(N=80)$ who were undergoing lower-limb orthopedic surgery [47]. The safety and pharmacokinetics of edoxaban $15 \mathrm{mg}$ once daily in patients with severe renal impairment were compared with edoxaban $30 \mathrm{mg}$ once daily in patients with mild renal impairment and fondaparinux $1.5 \mathrm{mg}$ in patients with severe renal impairment. By day 7 of treatment, edoxaban plasma concentrations overlapped between patients with severe and mild renal impairment who received edoxaban 15 and $30 \mathrm{mg}$, respectively. Bleeding events occurred in 6 $(20.7 \%), 10(33.3 \%)$ and $8(40.0 \%)$ patients in the edoxaban $15 \mathrm{mg}$, edoxaban $30 \mathrm{mg}$, and fondaparinux $1.5 \mathrm{mg}$ groups, respectively, but no major bleeding events occurred in any group. These results suggest that edoxaban $15 \mathrm{mg}$ once daily may be a suitable dose in patients undergoing orthopedic surgery who have severe renal impairment [47].

It is important to understand the safety and appropriate dose of a new antithrombotic agent such as edoxaban in patients undergoing hemodialysis treatment. Edoxaban has a plasma protein binding of $55 \%$ and renal clearance of $35 \%$ of administered dose and may be received by patients with severe renal impairment (with or without hemodialysis) [19]. An initial open-label study of patients with end-stage renal disease undergoing dialysis $(N=10)$ compared the safety and pharmacokinetics of edoxaban $15 \mathrm{mg}$ dosed $2 \mathrm{~h}$ prior to a $4 \mathrm{~h}$ hemodialysis session, with a day without hemodialysis [24]. When administered without and with hemodialysis, edoxaban exposures were comparable with an $\mathrm{AUC}_{0-\infty}$ of $692 \pm 150$ and $676 \pm 221 \mathrm{ng} \cdot \mathrm{h} / \mathrm{mL}$, respectively. Hemodialysis also had minimal effects on the clearance of edoxaban, with total clearance values of 24 and $23 \mathrm{~L} / \mathrm{h}$ with and without hemodialysis. The plasma protein binding of edoxaban was also similar with and without hemodialysis and ranged from 60 to $63 \%$. This study therefore indicated that hemodialysis has a minimal effect on the clearance of edoxaban, is not an effective mechanism of removal of edoxaban from the bloodstream, and additional dose reduction of edoxaban, to compensate for potential drug loss via hemodialysis, may not be necessary before hemodialysis [24].

\subsection{Phase III Clinical Trials}

A large number of phase III clinical studies have been performed with the NOACs. The studies performed in patients with AF, acute VTE, and undergoing orthopedic surgery are summarized in Tables 2, 3 and 4, respectively. In particular, studies with edoxaban have been recently completed in stroke prevention in patients with NVAF and also in the treatment of symptomatic VTE. Both these studies were specifically designed to simulate clinical practice as much as possible, with dose reduction at and after randomization, frequent INR monitoring and feedback, assessment of time in (INR) therapeutic range (TTR), comprehensive transition strategies at study end, and a flexible treatment duration in the Hokusai-VTE study [30, 33].

\subsubsection{Stroke Prevention in $A F$}

ENGAGE AF-TIMI 48 was a randomized, double-blind, double-dummy, international, non-inferiority study that compared two once-daily edoxaban regimens with wellcontrolled warfarin treatment (electronic supplementary Fig. 1, [48]). The primary efficacy endpoint was stroke or SEE, and the primary safety outcome was major bleeding. A total of 21,105 patients with NVAF (CHADS $_{2}$ score $\geq 2$ ) were randomized to edoxaban $60 \mathrm{mg}$ once daily (high-dose regimen), $30 \mathrm{mg}$ once daily (low-dose regimen) and dose-adjusted warfarin (INR 2.0-3.0). The 
overall mean $\mathrm{CHADS}_{2}$ score was 2.8; therefore, patients in ENGAGE AF-TIMI 48 were at moderate-to-high risk of stroke or systemic embolism. The demographic and clinical characteristics of the treatment groups were well balanced at baseline and the median duration of treatment exposure was 907 days, excluding interruptions; the median follow-up was 1,022 days ( 2.8 years). The criteria for dose reduction were concomitant treatment with a strong P-gp inhibitor (verapamil, quinidine or dronedarone), body weight $\leq 60 \mathrm{~kg}$ or creatinine clearance $30-50 \mathrm{~mL} / \mathrm{min}$. Patients in the high-dose group were reduced from edoxaban $60 \mathrm{mg}$ to $30 \mathrm{mg}$ once daily and those in the low-dose group were reduced from edoxaban $30 \mathrm{mg}$ to $15 \mathrm{mg}$ once daily in a double-blind manner. A total of 5,330 patients $(25.3 \%)$ received a reduced dose of edoxaban or matching placebo at randomization. After randomization, dose reduction occurred in $7.1 \%$ of patients. There were also significantly fewer drug interruptions in both edoxaban groups compared with warfarin ( $p<0.001$ for both comparisons). The median TTR of the warfarin group was $68.4 \%$ (interquartile range 56.5-77.4\%) (Table 2), indicating patients in the warfarin group received optimal treatment and acted as an effective active comparator for edoxaban. At the end of the trial, patients made the transition to open-label oral anticoagulant therapy with the use of a detailed transition plan and frequent monitoring and INR assessment for 30 days [30].

The primary efficacy outcome of stroke or SEE in the modified intention-to-treat (mITT) on-treatment analysis occurred at a rate of $1.50 \%$ per year in the well-controlled warfarin group, $1.18 \%$ per year in the high-dose edoxaban $60 \mathrm{mg}$ once-daily group $(p<0.001$ for non-inferiority; $p=0.02$ for superiority) and $1.61 \%$ per year in the lowdose edoxaban $30 \mathrm{mg}$ once-daily group ( $p=0.005$ for non-inferiority; $p$-value not significant for superiority) (Fig. 2a) [30]. In the overall ITT superiority analysis there was also a trend favoring high-dose edoxaban (1.57\%) versus warfarin $(1.80 \% ; p=0.08$ for superiority), while the trend was unfavorable for the low-dose edoxaban group $(2.04 \%)$ versus warfarin ( $p=0.10$ for superiority). The rates of hemorrhagic stroke in the high-dose and low-dose edoxaban groups $(0.26$ and $0.16 \%$, respectively) were statistically significantly lower than with warfarin $(0.47 \%$; $p<0.001)$. With regard to ischemic stroke, the edoxaban high-dose group $(1.25 \%)$ was not significantly different to warfarin $(1.25 \% ; p=0.97$ vs. warfarin), while the lowdose group $(1.77 \%)$ had a statistically significantly higher rate than the warfarin group ( $p<0.001$ vs. warfarin). Among patients who were dose reduced, there was no difference in primary events versus patients not dose reduced in either the high-dose group $(p=0.97$ for interaction) or the low-dose group ( $p=0.74$ for interaction)
[30]. In addition, death from a cardiovascular cause occurred at a rate of $3.17 \%$ in the warfarin group and at a significantly lower rate in both the high-dose edoxaban group $(2.74 \%$; hazard ratio [HR] 0.86 [95\% confidence interval [CI]: $0.77-0.97] ; p=0.013$ ) and low-dose edoxaban group (2.71\%; HR 0.85 [95\% CI: 0.76-0.96]; $p=0.008]$ ). There were also no differences observed in the rate of myocardial infarction between high-dose edoxaban and warfarin $(0.70 \%$ vs. $0.75 \%$; HR 0.94 [95\% CI: 0.74-1.19]; $p=0.60$ ) or between low-dose edoxaban and warfarin (0.89\% vs. $0.75 \%$; HR 1.19 [95\% CI: $0.95-1.49$ ]; $p=0.13$ ), which indicated the risk of myocardial infarction was not elevated during edoxaban treatment [30].

The ENGAGE AF-TIMI 48 study found a statistically significantly reduced rate of major bleeding between the high-dose $(2.75 \%)$ and low-dose $(1.61 \%)$ edoxaban groups versus well-controlled warfarin $(3.43 \%$; $p<0.001$ for both groups) (Fig. 2b). With regard to intracranial hemorrhage, the high-dose $(0.39 \%)$ and lowdose groups $(0.26 \%)$ both had significantly lower rates than the warfarin group $(0.85 \% ; p<0.001$ for both dose comparisons). Both edoxaban regimens also had statistically significantly lower rates of fatal bleeding, lifethreatening bleeding, major or CRNM bleeding and any overt bleeding than with warfarin $(p \leq 0.01$ for all comparisons). Compared with warfarin $(0.82 \%)$, the low-dose edoxaban group had a significantly lower rate of gastrointestinal bleeding $(1.23 \% ; p<0.001$ vs. warfarin), while a statistically higher rate was observed in the highdose edoxaban group ( $1.51 \% ; p=0.03$ vs. warfarin). With regard to patients who were dose-reduced, the rate of major bleeding was significantly lower compared with patients not dose-reduced in the high-dose $(p=0.02$ for interaction) and low-dose ( $p<0.01$ for interaction) edoxaban groups [30]. In addition, both the high-dose and low-dose edoxaban groups had a similar frequency of any or drug-related adverse events compared with the warfarin group. Regarding hepatic safety, both the high-dose and low-dose edoxaban groups also had a similar frequency of aspartate aminotransferase (AST) or alanine aminotransferase (ALT) $\geq 3 \times$ and total bilirubin $\geq 2 \times$ upper limit of normal versus the warfarin group. A similar pattern was also observed with the frequency of adjudicated hepatocellular injury, cholestasis and patients who satisfied Hy's Law criteria. Therefore, treatment with either high-dose or low-dose edoxaban was not associated with hepatic adverse events in patients with NVAF [30]. Overall, the efficacy and safety results with edoxaban in ENGAGE AF-TIMI 48 showed it was non-inferior to warfarin for stroke and SEE prevention in NVAF and was associated with a significantly lower risk of bleeding and death from a cardiovascular cause [30]. 


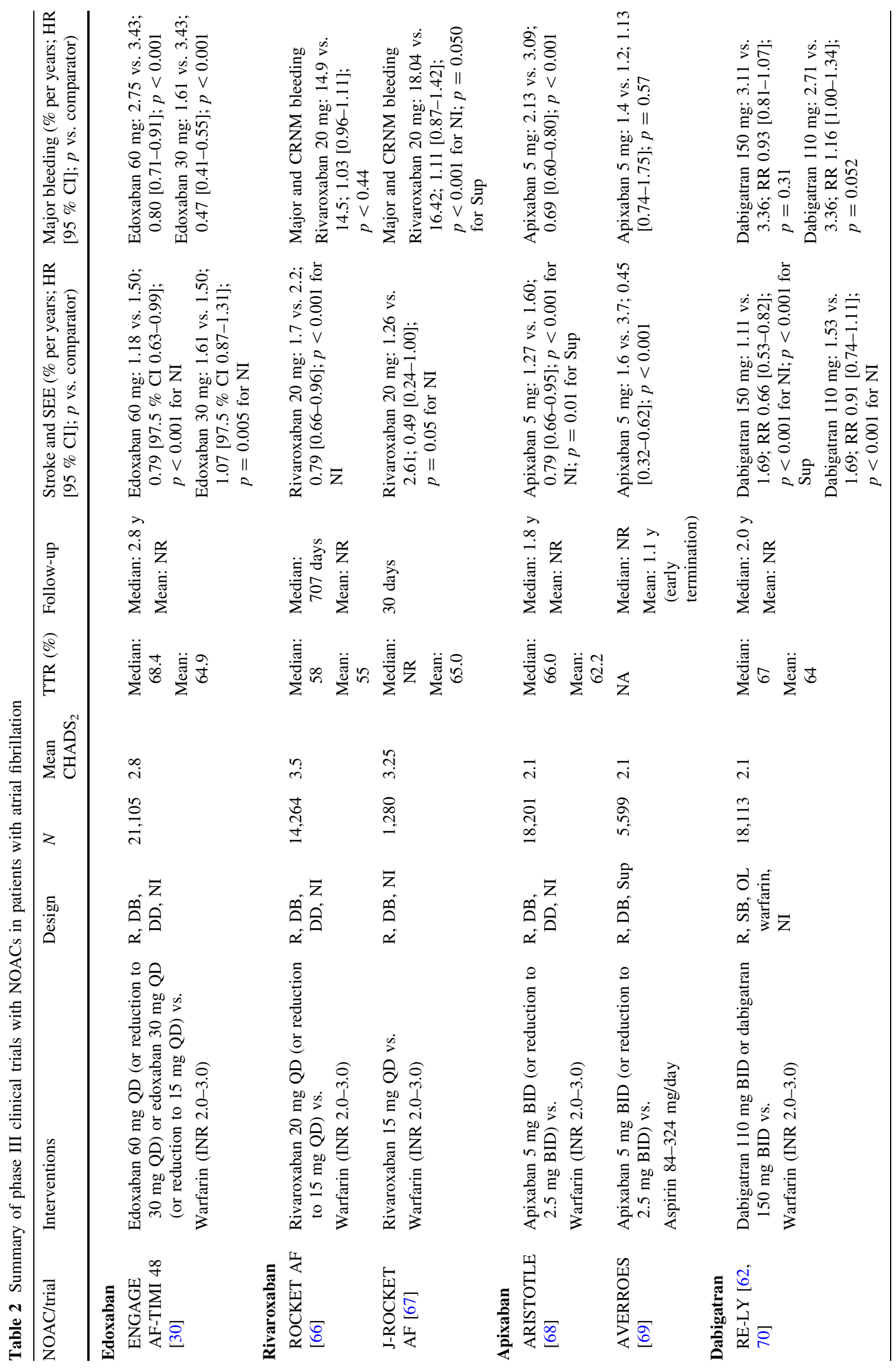




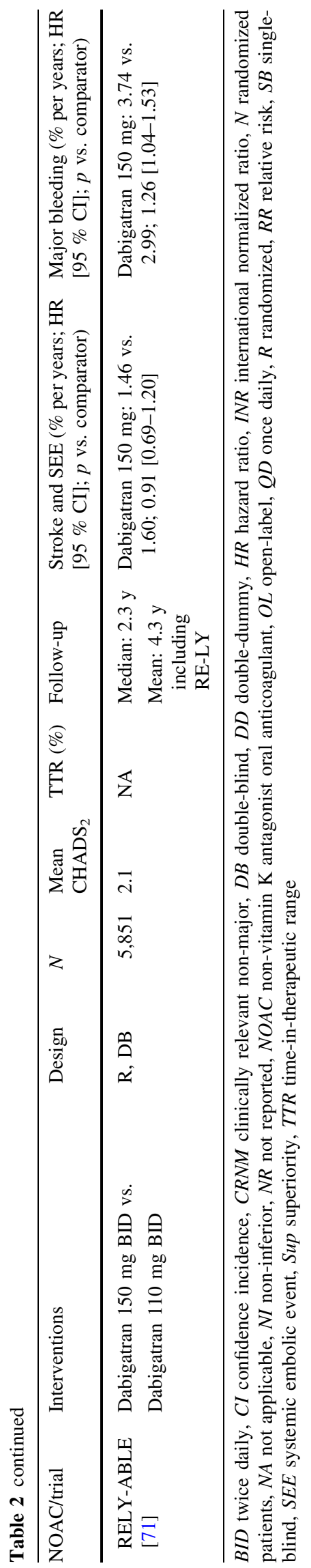

\subsubsection{Treatment of Symptomatic VTE}

Hokusai-VTE was the largest study ever conducted in acute symptomatic VTE, with 8,292 patients randomized internationally. The study had a randomized, double-blind, double-dummy, parallel-group, non-inferiority design, a flexible treatment duration of 3-12 months and primary analysis of all patients at 12 months (electronic supplementary Fig. 2). Hokusai-VTE compared the efficacy and safety of an enoxaparin/unfractionated heparin lead-in followed by edoxaban $60 \mathrm{mg}$ once daily versus standard of care [enoxaparin/unfractionated heparin lead-in followed by warfarin (INR 2.0-3.0)] in the treatment of symptomatic VTE, with a primary efficacy outcome of recurrent symptomatic VTE and a primary safety outcome of major or CRNM bleeding [33]. Patients in the edoxaban group who qualified for dose reduction (creatinine clearance $30-50 \mathrm{~mL} / \mathrm{min}$, body weight $\leq 60 \mathrm{~kg}$ or concomitant administration of strong P-gp inhibitors) were switched to edoxaban $30 \mathrm{mg}$ once daily in a double-blind manner. At randomization, approximately $17 \%$ of patients in each treatment group were dose-reduced and approximately $65 \%$ of patients had an unprovoked VTE index event, who were at a particularly high risk of recurrent disease [15]. Other baseline characteristics of patients in each treatment group were also similar. Approximately $40 \%$ of patients randomized in HokusaiVTE had PE, of those $46 \%$ had extensive PE (defined as involvement of multiple lobes with $25 \%$ or more of the entire vasculature), and $42 \%$ of DVT patients were classified as extensive (defined as an event in which the most proximal site was the common femoral or iliac vein). Hokusai-VTE had a flexible treatment duration: $40 \%$ of patients received treatment for the entire duration of 12 months, while over $61 \%$ received treatment for over 6 months. In the warfarin group, the mean TTR was $63.5 \%$, indicating that these patients were well-controlled in Hokusai-VTE [33].

Hokusai-VTE demonstrated that edoxaban $60 \mathrm{mg}$ once daily after initial treatment with heparin was non-inferior to well-controlled standard therapy and caused significantly less bleeding in a broad range of patients with VTE. The rate of symptomatic recurrent VTE was $3.2 \%$ per year in the edoxaban group, compared with $3.5 \%$ per year in the standard therapy group $(p<0.001$ for non-inferiority) (Fig. 2a). Edoxaban $60 \mathrm{mg}$ once daily was also associated with significantly fewer major or CRNM bleeding events compared with well-controlled standard therapy $(8.5 \%$ per year vs. $10.3 \%$ per year, $p=0.004$ for superiority) (Fig. 2b) [33]. Edoxaban was effective across a broad range of DVT and PE patients and over a flexible treatment duration of 3-12 months. Compared with VTE recurrence rates in the overall analysis of patients treated with 


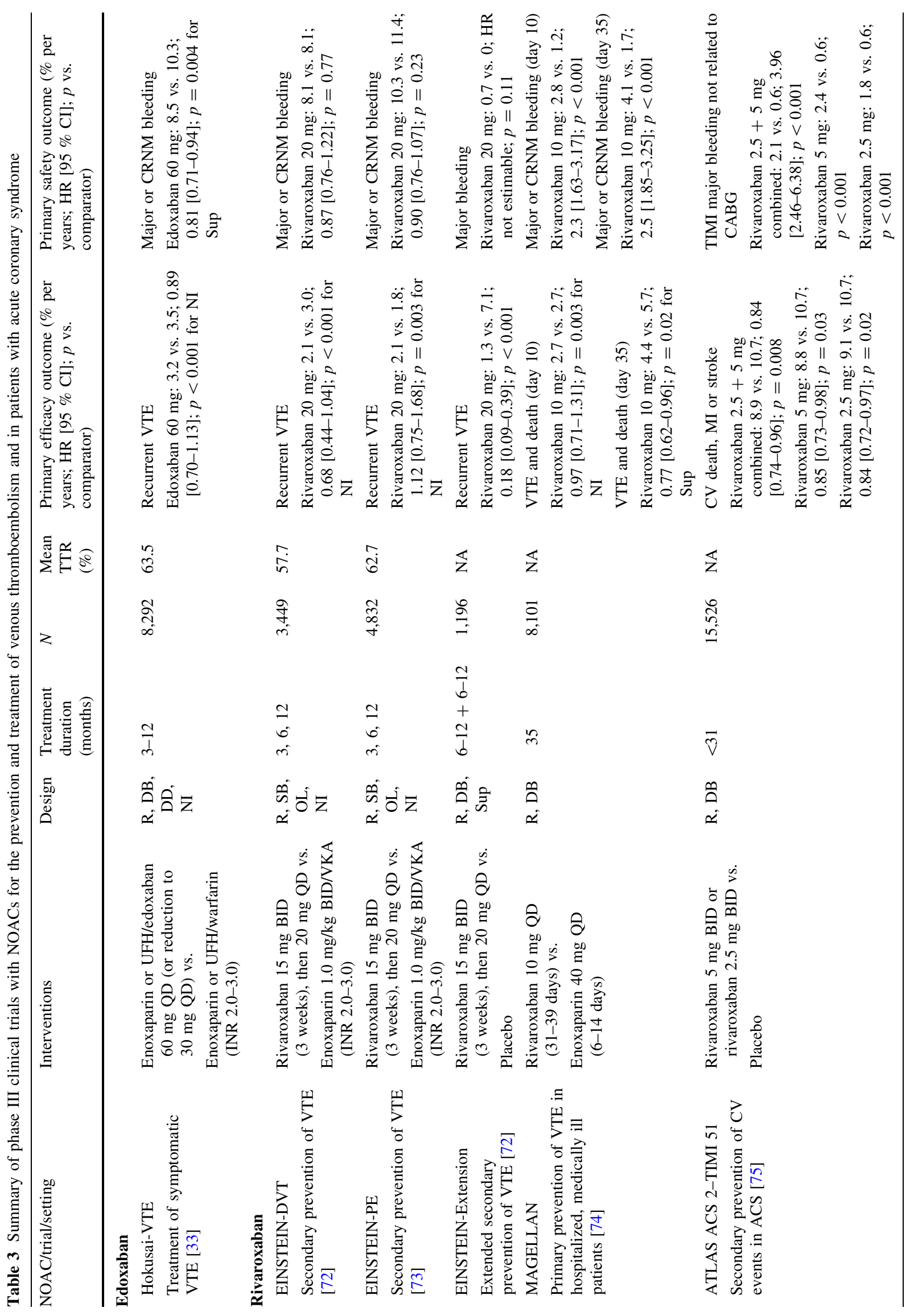




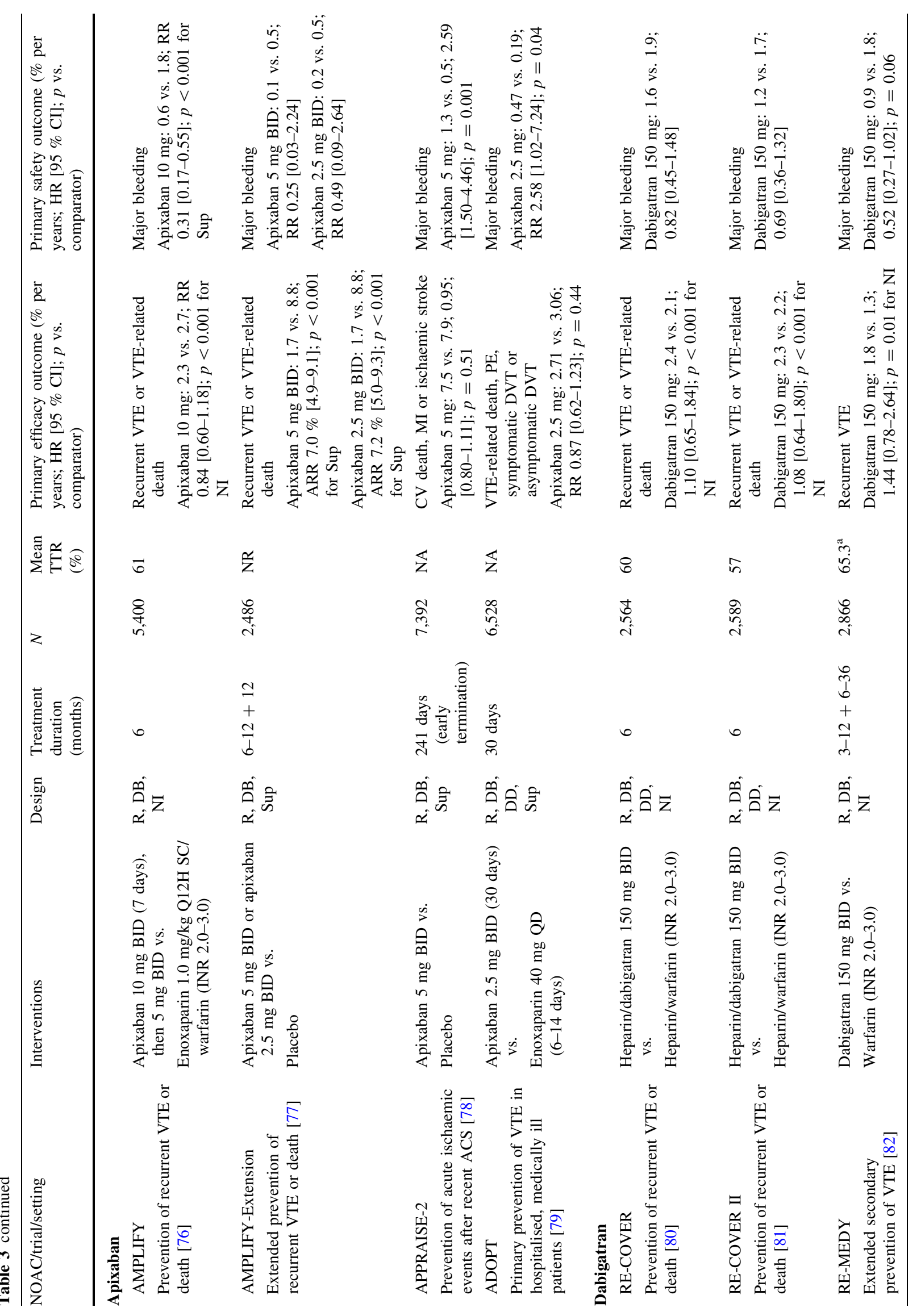




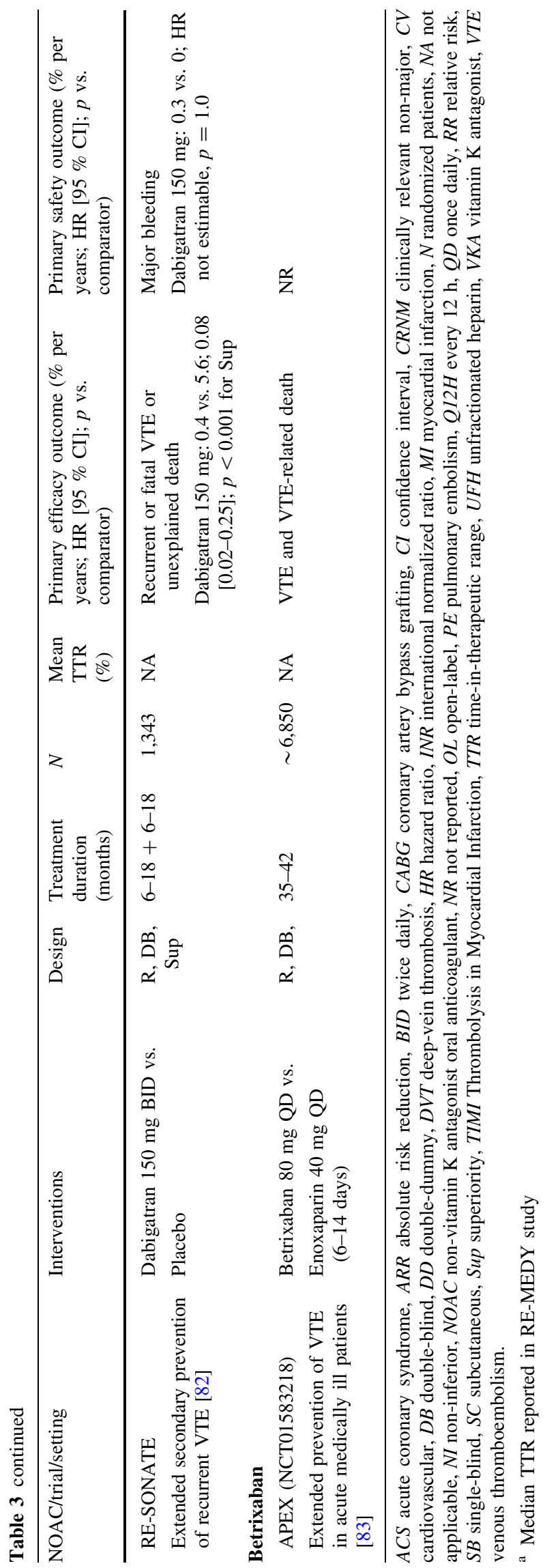

edoxaban or warfarin for 3-12 months, those observed in the on-treatment analysis of patients treated for 12 months were lower in both the edoxaban (3.2\% vs. $1.6 \%$ per year) and warfarin (3.5\% vs. $1.9 \%$ per year) arms, with edoxaban also non-inferior to warfarin in the on-treatment analysis $(p<0.001$ for non-inferiority). With regard to patients with a DVT index event, recurrent VTE was observed in approximately $3.4 \%$ and $3.3 \%$ of the edoxaban and warfarin groups [HR $1.02(0.75-1.38)]$, respectively. In patients with a PE index event, recurrent VTE was recorded in $2.8 \%$ and $3.9 \%$ of the edoxaban and warfarin groups, respectively, with no statistically significant difference found [HR $0.75(0.50-1.06)]$. Edoxaban also demonstrated robust efficacy versus warfarin $(3.3 \%$ vs. $6.2 \%$ per year) in the subgroup of PE patients with evidence of right ventricular dysfunction $\mathrm{N}$-terminal of the prohormone brain natriuretic peptide (NT-proBNP level $\geq 500 \mathrm{pg} / \mathrm{mL}$ ), which was supported by an analysis in a large subset of patients assessed by computed tomography $(n=1,002)$. Among patients who were dose-reduced to edoxaban $30 \mathrm{mg}$ once daily, the rates of VTE recurrence, major bleeding and major or CRNM bleeding were all lower in the edoxaban group than in the warfarin group, suggesting that patient-specific dosing of edoxaban maintains efficacy and safety [33]. The rate of serious adverse events, serious adverse events leading to discontinuation and adverse events occurring on treatment were similar in the edoxaban and warfarin groups. Regarding hepatic safety, the edoxaban group had a similar frequency of ALT $\geq 3 \times$ or $\geq 5 \times$ upper limit of normal, ALT or AST $\geq 3 \times$ and total bilirubin $\geq 2 \times$ upper limit of normal, as well as patients who satisfied Hy's Law criteria compared with the warfarin group. Therefore, treatment with edoxaban was not associated with hepatic adverse events in patients with symptomatic VTE [33].

In addition, a pre-specified post hoc analysis of patients with active or a history of cancer randomized in HokusaiVTE $(n=771)$ assessed the efficacy and safety of edoxaban in this large subgroup that comprised $9.3 \%$ of patients [49]. Recurrent VTE occurred in $3.7 \%$ of patients given edoxaban and $7.1 \%$ who received warfarin. Major or CRNM bleeding occurred in $12.4 \%$ of the edoxaban group and a higher proportion of $18.8 \%$ of the warfarin group. This analysis suggested that edoxaban was as effective, and possibly more effective, than warfarin in cancer patients with VTE, and may potentially reduce bleeding versus warfarin in such patients [49]. Overall, the Hokusai-VTE study, which had a flexible treatment duration to simulate routine clinical practice as much as possible, indicated edoxaban was an effective, well tolerated treatment, with a lower risk of bleeding than standard warfarin therapy, in a broad spectrum of acute symptomatic VTE patients [33]. 


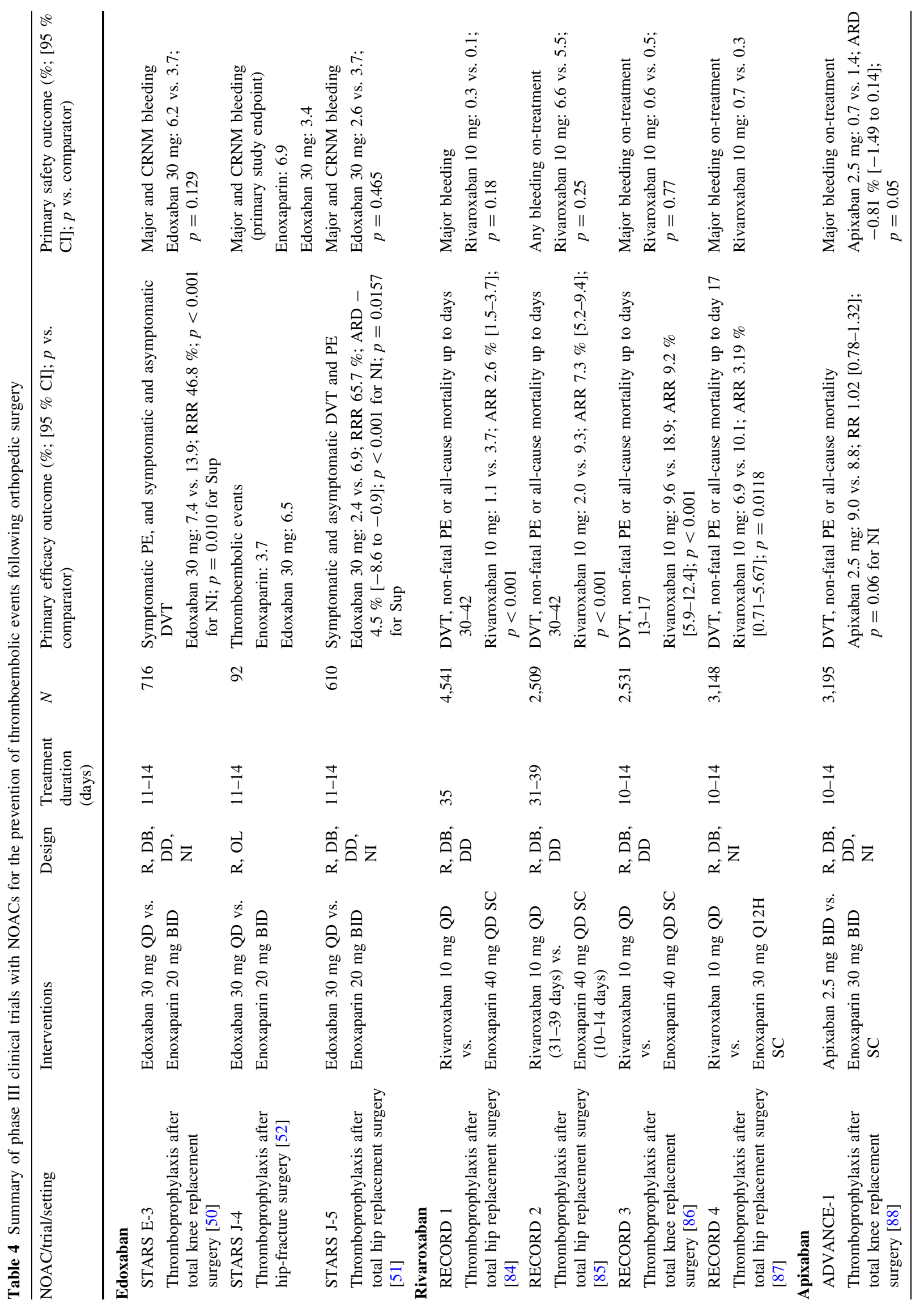




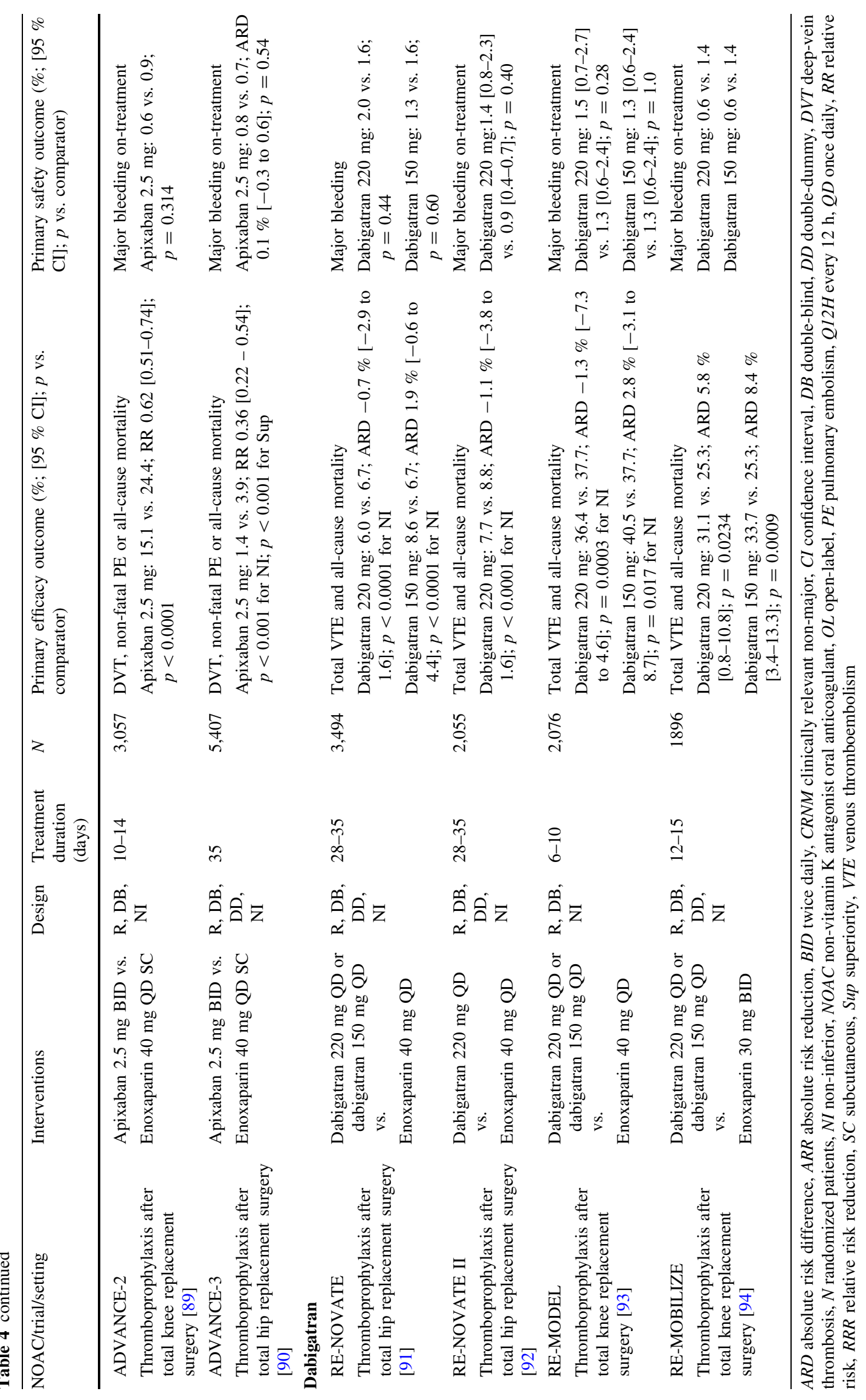


Fig. 2 Kaplan-Meier curves for primary endpoints in ENGAGE AF-TIMI 48.

a Stroke and systemic embolism in the ITT analysis set, overall study period; b major bleeding in the safety analysis set, ontreatment period. High-dose edoxaban: $60 \mathrm{mg}$ QD (or reduction to $30 \mathrm{mg} \mathrm{QD}$ ); lowdose edoxaban: $30 \mathrm{mg}$ QD (or reduction to $15 \mathrm{mg} \mathrm{QD}$ ); dose reduction criteria: moderate renal impairment (creatinine clearance $30-50 \mathrm{~mL} / \mathrm{min}$ ), body weight $\leq 60 \mathrm{~kg}$ or while taking a strong P-glycoprotein inhibitor. $C I$ confidence interval, $H R$ hazard ratio, ITT intention-totreat, $Q D$ once daily, TTR time in therapeutic ratio. Reproduced from Giugliano et al. [30], with permission
A

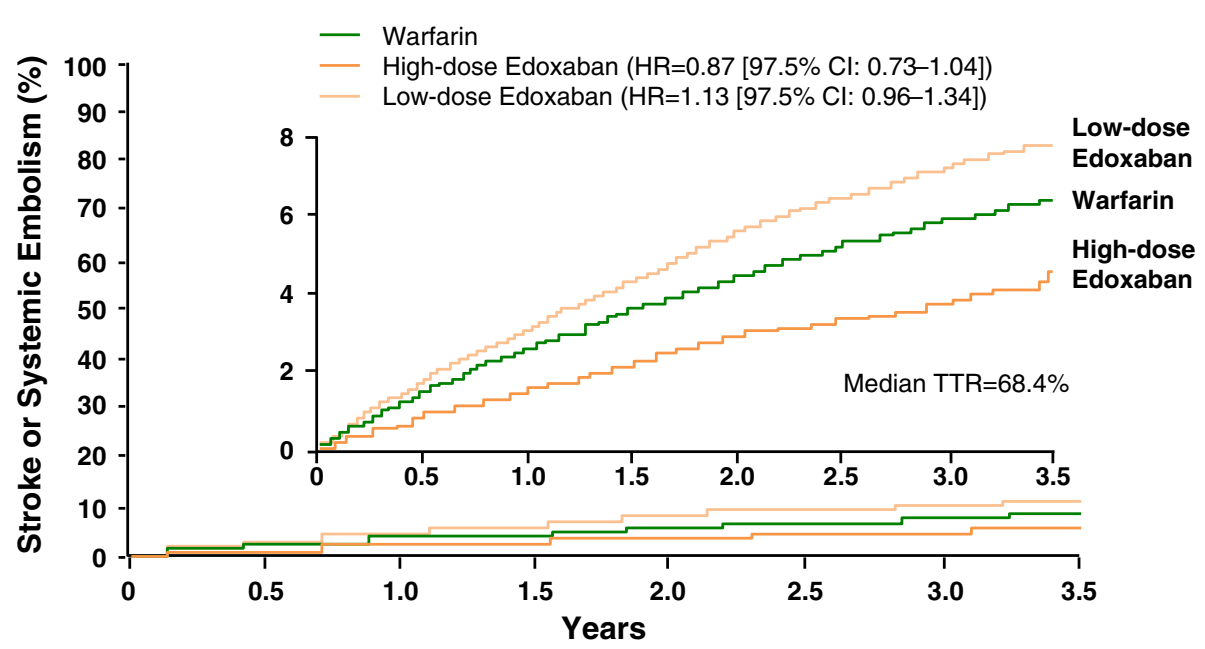

No. at Risk

$\begin{array}{lllllllll}\text { Warfarin } & 7036 & 6798 & 6615 & 6406 & 6225 & 4593 & 2333 & 536 \\ \begin{array}{l}\text { High-dose } \\ \text { Edoxaban }\end{array} & 7035 & 6816 & 6650 & 6480 & 6283 & 4659 & 2401 & 551 \\ \begin{array}{l}\text { Low-dose } \\ \text { Edoxaban }\end{array} & 7034 & 6815 & 6631 & 6461 & 6277 & 4608 & 2358 & 534\end{array}$

B

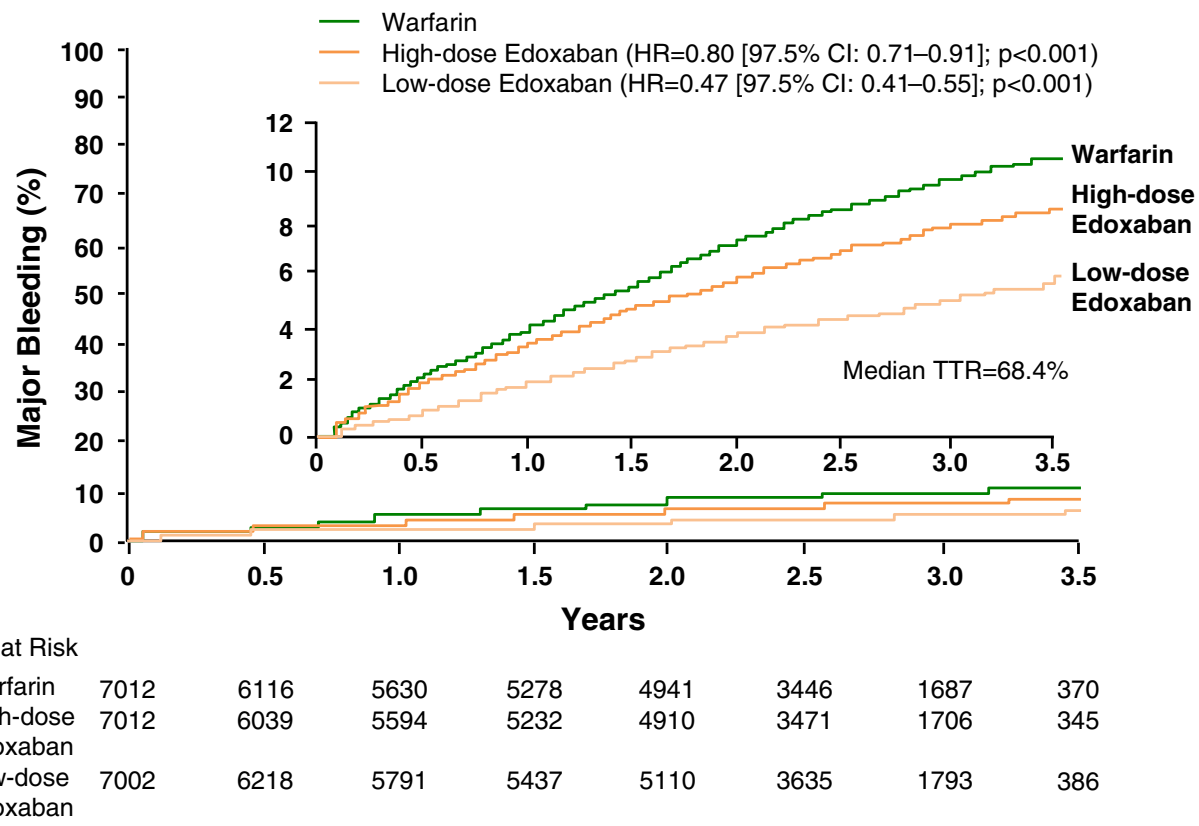

\subsubsection{Prevention of VTE After Orthopedic Surgery}

A comprehensive phase III clinical program comprising the randomized, double-blind, double-dummy STARS E-3, STARS J-4 and STARS J-5 studies of edoxaban, established its efficacy and safety in the prevention of VTE after orthopedic surgery. The STARS E-3 trial in patients undergoing total knee replacement surgery randomized patients $(N=716)$ to edoxaban $30 \mathrm{mg}$ once daily or subcutaneous enoxaparin $20 \mathrm{mg}$ every $12 \mathrm{~h}$, for 11-14 days
[50]. The primary efficacy endpoint was symptomatic VTE. VTE events occurred in $13.9 \%$ of the enoxaparin group and in $7.4 \%$ of patients receiving edoxaban treatment, which was non-inferior $(p<0.001)$ and superior $(p=0.010)$ to enoxaparin treatment. Major bleeding occurred in $1.1 \%$ of the edoxaban group and $0.3 \%$ of the enoxaparin group ( $p=0.373$ vs. edoxaban), and major and CRNM bleeding occurred in $6.2 \%$ of patients who received edoxaban and $3.7 \%$ of the enoxaparin group ( $p=0.129$ vs. edoxaban). The STARS E-3 trial therefore 
Fig. 3 Kaplan-Meier curves for primary endpoints in Hokusai-VTE. a recurrence of VTE; b major or CRNM bleeding. Edoxaban dose: $60 \mathrm{mg}$ QD (or reduction to $30 \mathrm{mg}$ QD), dose reduction criteria: moderate renal impairment (creatinine clearance $30-50 \mathrm{~mL} / \mathrm{min}$ ), body weight $\leq 60 \mathrm{~kg}$, or while taking a strong P-glycoprotein inhibitor. $C I$ confidence interval, $C R N M$ clinically relevant non-major, $H R$ hazard ratio, $N I$ non-inferiority, $Q D$ once daily, TTR time in therapeutic ratio, VTE venous thromboembolism. Reproduced from Hokusai-VTE Investigators [33], with permission
A

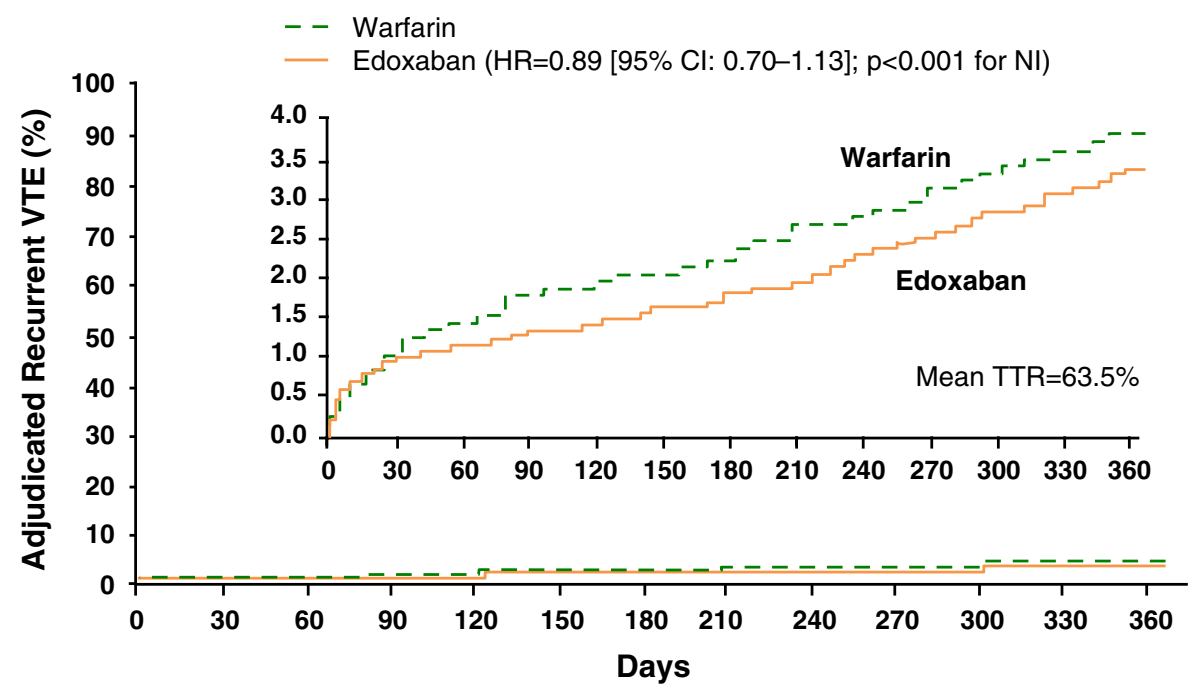

No. at Risk

$\begin{array}{llllllllllllll}\text { Edoxaban } & 4118 & 4050 & 4024 & 4002 & 3985 & 3974 & 3959 & 3885 & 3692 & 3524 & 3358 & 3190 & 2981\end{array}$

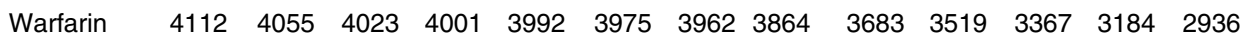

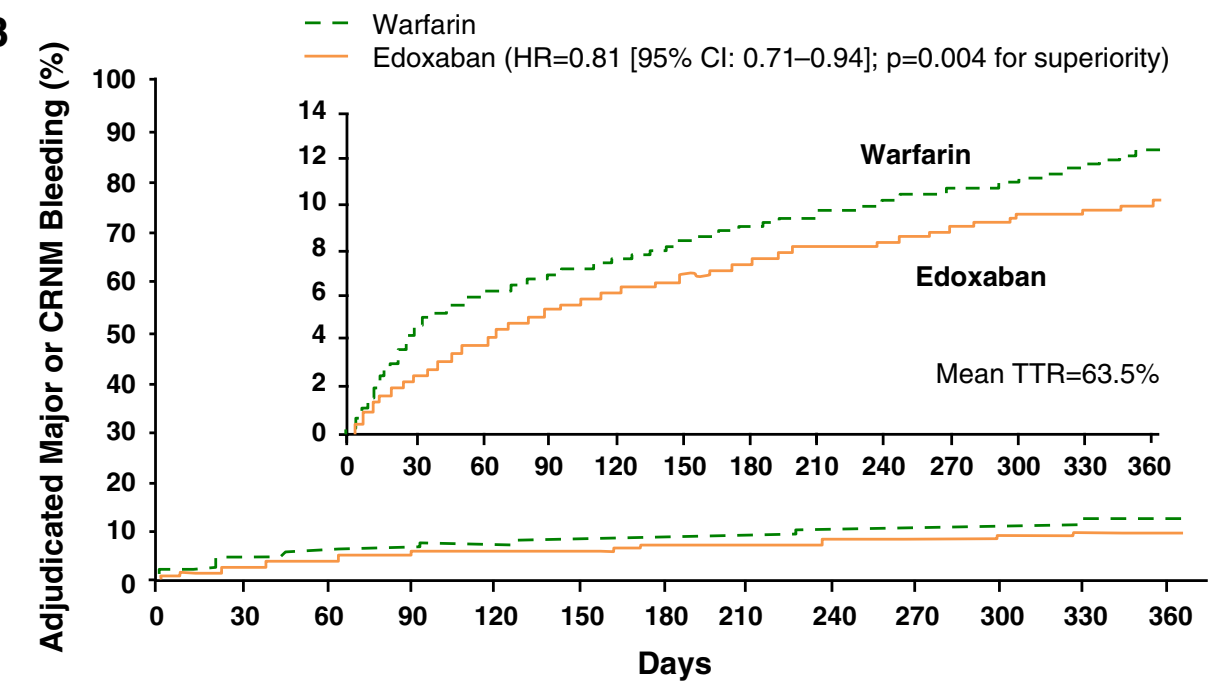

No. at Risk

$\begin{array}{llllllllllllll}\text { Edoxaban } & 4118 & 3840 & 3695 & 3587 & 3382 & 3308 & 3038 & 2192 & 2043 & 1904 & 1764 & 1650 & 1241\end{array}$

$\begin{array}{llllllllllllll}\text { Warfarin } & 4122 & 3757 & 3627 & 3522 & 3313 & 3218 & 2979 & 2165 & 2007 & 1883 & 1754 & 1613 & 1212\end{array}$

demonstrated edoxaban was superior to enoxaparin in the prevention of VTE after total knee replacement surgery, without a significant increase in bleeding rates [50].

The STARS J-5 study had an analogous design to STARS E-3, but was conducted in patients $(N=610)$ undergoing total hip replacement surgery [51]. VTE events occurred in $6.9 \%$ of patients who received enoxaparin and $2.4 \%$ of patients who received edoxaban, which was noninferior $(p<0.001)$ and superior $(p=0.0157)$ to enoxaparin. Major and CRNM bleeding occurred in $2.6 \%$ of patients who received edoxaban and $3.7 \%$ of the enoxaparin group ( $p=0.475$ vs. edoxaban), while major bleeding occurred in $0.7 \%$ of the edoxaban group and $2.0 \%$ of the enoxaparin group. The STARS J-5 trial therefore demonstrated edoxaban was superior to enoxaparin in the prevention of VTE after total hip replacement surgery and was associated with a similar risk of bleeding [51] (Fig. 3).

STARS J-4 was a multicenter, open-label, safety study in Japanese patients $(N=92)$ undergoing hip-fracture surgery, in which patients were randomized to edoxaban $30 \mathrm{mg}$ once daily or subcutaneous enoxaparin $2,000 \mathrm{IU}$ every $12 \mathrm{~h}$, for 11-14 days [52]. The incidence of major and CRNM bleeding was $3.4 \%$ in the edoxaban group and 
$6.9 \%$ in the enoxaparin group, while any bleeding event occurred in 25.4 and $17.2 \%$ of patients, respectively. There was one episode of major bleeding in each group and the rate of asymptomatic thromboembolic events was $6.5 \%$ in the edoxaban group and $3.7 \%$ in the enoxaparin group, with no symptomatic events observed. Edoxaban therefore demonstrated similar safety and efficacy to enoxaparin in Japanese patients undergoing hip-fracture surgery [52]. Overall, the STARS study program demonstrated that edoxaban was more effective than enoxaparin in the prevention of VTE following total hip or knee replacement surgery and was associated with a similar risk of bleeding. The STARS studies supported regulatory approval of edoxaban $30 \mathrm{mg}$ once daily for the prevention of VTE following orthopedic surgery in Japan in 2011.

\subsection{Phase IV Postmarketing Surveillance}

\subsubsection{Prevention of VTE After Orthopedic Surgery in Japan}

A postmarketing safety analysis of patients treated with edoxaban $30 \mathrm{mg}$ once daily for the prevention of VTE after orthopedic surgery has been conducted in Japan [53]. This study assessed the first 6 months of postmarketing experience, during which approximately 20,000 patients received edoxaban. The mean age of patients was 74.2 years, mean weight was $59.4 \mathrm{~kg}$, and approximately $70 \%$ were female. A total of 67 adverse events (51 bleeding events) were observed in 56 patients $(0.3 \%$ of population). Therefore, this postmarketing analysis found no safety signals that were not previously observed in clinical studies with edoxaban $30 \mathrm{mg}$ once daily [53].

\section{Management of Bleeding Complications}

Guidance on the emergency reversal of anticoagulant effects from NOAC treatment has recently been formulated by a group of experts participating in the Thrombosis and Hemostasis Summit of North America [54]. In the case of overdose, activated charcoal may be administered within $3 \mathrm{~h}$ of NOAC dosing to reduce gastrointestinal absorption. For patients who experience major bleeding, treatment discontinuation and supportive care were recommended [54].

At present there is no specific antidote available for the anticoagulant effects of edoxaban, but studies of potential agents are currently underway. However, initial preclinical studies with activated recombinant human factor VII (rhFVIIa), a prothrombin complex concentrate (PCC, PPSB-HT) and a prothrombin complex concentrate with activated factor VII (aPCC; FEIBA), found they can significantly reduce the changes in PT caused by edoxaban in a concentration-dependent manner [55]. It has also been suggested that a recombinant factor Xa protein (andexanet alfa, PRT4445), which is catalytically inactive and does not inhibit factor Xa, may be a potential reversal agent for factor Xa inhibition. Preliminary results with this agent suggest a dose-dependent reversal of factor Xa inhibition with rivaroxaban [56]. A phase II proof-of-concept study in healthy volunteers to evaluate the safety, tolerability, pharmacokinetics and pharmacodynamics of andexanet alfa after dosing of a direct or indirect factor Xa inhibitor is currently ongoing (NCT01758432). Recent results from this ongoing clinical trial demonstrate that andexanet alfa is able to dose-dependently, partially reverse the anticoagulant effects of rivaroxaban and apixaban, as assessed by pharmacodynamic markers, in healthy subjects [57]. In addition, a synthetic small molecule (PER977) has been designed and synthesized for the reversal of anticoagulation with NOACs. Preliminary in vitro studies with PER977 and assessment of rat-tail bleeding models have shown that it directly and specifically binds the NOACs to reverse anticoagulant activity. PER977 reverses the anticoagulant effects of edoxaban within 20 minutes after administration. It also exhibits no binding to any human plasma coagulation factors or albumin and has shown no procoagulant properties [58, 59]. A first-in-human clinical trial to assess the safety and efficacy of PER977 $3 \mathrm{~h}$ after administration of edoxaban $60 \mathrm{mg}$ in healthy human volunteers is ongoing (NCT01826266).

\section{Discussion}

The prevention of thromboembolic events is a significant global healthcare issue. Although VKAs have been used for several decades and are effective in preventing thromboembolic events, they have considerable limitations in clinical practice [1]. Thus, the NOACs, including edoxaban, were developed to provide effective, convenient anticoagulation treatment, with reduced bleeding risk compared with warfarin.

The multinational edoxaban phase III clinical studies ENGAGE AF-TIMI 48 and Hokusai-VTE were completed in 2013. ENGAGE AF-TIMI 48 compared a high-dose and low-dose edoxaban dosing regimen with warfarin in patients with $\mathrm{AF}$ at moderate-to-high risk of stroke. Both high-dose and low-dose edoxaban regimens were noninferior to warfarin for stroke prevention, and also associated with a significantly lower rate of bleeding and cardiovascular mortality [30]. Regarding efficacy observations in the high-dose edoxaban arm, a reduction in risk of $21 \%$ for stroke or SEE, $46 \%$ for hemorrhagic stroke, $14 \%$ for cardiovascular mortality and $13 \%$ for intracranial 
hemorrhage was found compared with well-controlled warfarin. In terms of safety, a reduction in risk of $20 \%$ for major bleeding, $45 \%$ for fatal bleeding and $53 \%$ for intracranial bleeding was observed in the high-dose edoxaban arm versus well-controlled warfarin [30]. The Hokusai-VTE study in a broad spectrum of patients with acute symptomatic VTE compared initial heparin and edoxaban $60 \mathrm{mg}$ once daily with initial heparin and warfarin treatment for a flexible treatment duration of 3-12 months. Edoxaban was non-inferior to warfarin in the prevention of recurrent VTE and was also associated with a significantly lower bleeding rate than warfarin [33]. The risk of recurrent VTE was lowered by $11 \%$, major or CRNM bleeding by $19 \%$ and any bleeding by $18 \%$ in the edoxaban group compared with warfarin [33]. In addition, Hokusai-VTE showed that the duration of treatment for symptomatic VTE is an important factor to consider in every patient to balance the risk of recurrence with bleeding. The rate of events was lower in the on-treatment analysis of patients who remained on edoxaban or warfarin treatment for 12 months compared with the overall analysis of patients who were treated for 3-12 months. As a large proportion of patients had extensive PE, these data may support the continuation of therapy [33]. It was notable that the Hokusai-VTE study included a substantial subpopulation with cancer and, in this subgroup, patients who received edoxaban had a lower rate of VTE recurrence and significantly lower rate of bleeding than those in the warfarin group [49]. Dose reduction was performed throughout ENGAGE AF-TIMI 48 and Hokusai-VTE in patients at risk of overexposure (creatinine clearance $30-50 \mathrm{~mL} / \mathrm{min}$, body weight $\leq 60 \mathrm{~kg}$ or concomitant treatment with a strong P-gp inhibitor). Efficacy was maintained in patients who were dose reduced in both studies, and in ENGAGE AF-TIMI 48 a significantly lower rate of bleeding was observed compared with patients who were not dosereduced [30, 33]. Therefore, patient-tailored dosing of edoxaban may provide an effective option in clinical practice, which could also help lower the risk of bleeding.

The ENGAGE AF-TIMI 48 and Hokusai-VTE studies build upon the STARS phase III clinical program in Japan, in which edoxaban was superior to enoxaparin in the prevention of VTE after orthopedic surgery, with a similar risk of bleeding [51, 60]. Edoxaban $30 \mathrm{mg}$ once daily is currently approved for the prevention of VTE after orthopedic surgery in Japan, and postmarketing surveillance data has not found any unforeseen safety signals and a limited number of bleeding events with edoxaban [53]. Marketing authorization for once-daily edoxaban for stroke prevention in $\mathrm{AF}$ and the treatment and prevention of recurrence of VTE in the US and EU was requested in January 2014.

A major limitation of VKA treatment is an increased risk of bleeding. In patients with AF, VKA therapy increases the risk of major bleeding and intracranial hemorrhage by $0.3-0.5 \%$ and $0.2 \%$ per year, respectively [3]. This limits its use because physicians can be reluctant to prescribe warfarin to the elderly or patients at heightened risk of bleeding, such as those with a history of falls, and intracranial or gastrointestinal hemorrhage [61]. In clinical practice, bleeding events are also a reason to stop anticoagulant treatment [54]. Therefore, the observation of reduced bleeding with edoxaban versus VKA treatment in a broad spectrum of patients with acute VTE, as well as patients with NVAF at moderate-to-high risk of stroke, may be an important benefit for patients. In addition, edoxaban treatment has the convenience of once-daily oral administration, which may help ensure patient adherence to treatment.

Edoxaban has a predictable pharmacokinetic profile and dose response that allows treatment without the need for regular coagulation monitoring, which has been a major limitation to VKA treatment for decades [1, 18, 19]. However, at present there is no validated test to assess the antithrombotic effect of any of the NOACs. The availability of such a test might be helpful in emergency situations such as serious bleeding and surgery, or special clinical situations such as suspected overdose, patients with renal/hepatic insufficiency or with uncertainty about NOAC administration. The management of bleeding complications with an NOAC such as edoxaban would also require a rapid and safe reversal agent for factor Xa inhibition. In this regard, a potential agent (PER977) has demonstrated effective reversal of factor $\mathrm{Xa}$ inhibition in vitro and in a rat-tail bleeding model $[58,59]$. Currently, PER977 is being assessed after edoxaban administration in a clinical study (NCT01826266) and andexanet alfa is also being investigated after administration of various NOACs (NCT01758432). The availability of an effective reversal agent at the time of edoxaban regulatory approval in the US, EU and Japan would prove helpful in emergency situations where rapid reversal of anticoagulation is required.

The phase III clinical studies with dabigatran, rivaroxaban, apixaban and edoxaban for stroke prevention in patients with AF and also for prevention of recurrence in patients with acute VTE have recently been assessed in two meta-analyses [16, 17]. With regard to stroke prevention in patients with $\mathrm{AF}$, the NOACs overall provided significant reductions in the rate of stroke or systemic embolism, hemorrhagic stroke, all-cause mortality and intracranial hemorrhage compared with warfarin. In addition, the overall relative efficacy and safety of the NOACs was consistent across a wide range of patients with $\mathrm{AF}$, including those with diabetes, moderate and mild renal impairment, $\mathrm{CHADS}_{2}$ score 3-6 and center-based TTR $<66 \%$. A direct comparison of the phase III studies is difficult because each had patients with a different mean 
$\mathrm{CHADS}_{2}$ score and other major differences in design, such as the open-label warfarin, blinded dabigatran RE-LY trial and randomized, double-blind, double-dummy ENGAGE AF-TIMI 48 study (Table 2) [16]. In the treatment of patients with acute VTE, the NOACs overall had comparable efficacy to VKA therapy in the prevention of VTE recurrence, fatal $\mathrm{PE}$ and in the rate of all-cause mortality. However, benefits with NOAC therapy in VTE were observed with significantly lower bleeding rates, as in patients with AF [17]. Taken together, the NOACs provide important benefits in safety and bleeding compared with VKA treatment, and offer new options for the prevention of thromboembolic events.

\section{Conclusions}

Edoxaban once daily is a well-tolerated inhibitor of factor $\mathrm{Xa}$ that has demonstrated non-inferior efficacy together with a superior bleeding profile compared with an optimized standard of care for both stroke prevention in patients with NVAF and the treatment and prevention of symptomatic recurrent VTE. Edoxaban also offers several additional benefits over traditional VKA therapy for stroke prevention in patients with NVAF, of which significant reductions in hemorrhagic stroke, intracranial bleeding and cardiovascular mortality, and the absence of laboratory monitoring may be of key importance to patients. Marketing authorization for once-daily edoxaban has been requested in the US, EU and Japan for stroke prevention in patients with NVAF and the treatment and prevention of recurrence of VTE. Given the ENGAGE AF-TIMI 48 and Hokusai-VTE studies were designed to simulate clinical practice and showed edoxaban once daily was effective and safe in two large populations of patients at moderate-to-high risk of thromboembolic events, edoxaban may prove to be a key addition to antithrombotic therapy.

Acknowledgments We thank Faysal Riaz, PhD, of inScience Communications, Springer Healthcare, UK, who provided assistance with drafting and editing of the manuscript. This assistance was funded by Daiichi Sankyo Europe GmbH.

Conflicts of Interest Henri Bounameaux reports having received research grants from Bayer Pharma and Daiichi Sankyo, and honoraria for consultancy or lectures from Bayer Pharma, Daiichi Sankyo and Pfizer. A. John Camm reports having participated in the ENGAGE AF-TIMI 48 trial and has acted as a consultant for Daiichi Sankyo.

Open Access This article is distributed under the terms of the Creative Commons Attribution Noncommercial License which permits any noncommercial use, distribution, and reproduction in any medium, provided the original author(s) and the source are credited.

\section{References}

1. De Caterina R, Husted S, Wallentin L, Andreotti F, Arnesen H, Bachmann F, et al. Vitamin $\mathrm{K}$ antagonists in heart disease: current status and perspectives (Section III). Position Paper of the ESC Working Group on Thrombosis-Task Force on Anticoagulants in Heart Disease. Thromb Haemost. 2013;110(6):1087-107.

2. Grip LT, Ruff CT, Giugliano RP. New oral antithrombotic strategies: 2013 update on atrial fibrillation. Hot Topics Cardiol. 2013;8(31):7-19.

3. Schulman S, Beyth RJ, Kearon C, Levine MN; American College of Chest Physicians. Hemorrhagic complications of anticoagulant and thrombolytic treatment: American College of Chest Physicians evidence-based clinical practice guidelines (8th edition). Chest. 2008;133(6 Suppl):257S-98S.

4. Kimmel SE, French B, Kasner SE, Johnson JA, Anderson JL, Gage BF, et al. A pharmacogenetic versus a clinical algorithm for warfarin dosing. N Engl J Med. 2013;369(24):2283-93.

5. Pirmohamed M, Burnside G, Eriksson N, Jorgensen AL, Toh CH, Nicholson T, et al. A randomized trial of genotype-guided dosing of warfarin. N Engl J Med. 2013;369(24):2294-303.

6. Verhoef TI, Ragia G, de Boer A, Barallon R, Kolovou G, Kolovou $\mathrm{V}$, et al. A randomized trial of genotype-guided dosing of acenocoumarol and phenprocoumon. $\mathrm{N}$ Engl $\mathrm{J}$ Med. 2013;369(24):2304-12.

7. Frykman V, Beerman B, Ryden L, Rosenqvist M, Medical Products Agency, Swedish Society of Cardiology. Management of atrial fibrillation: discrepancy between guideline recommendations and actual practice exposes patients to risk for complications. Eur Heart J. 2001;22(20):1954-9

8. Wilke T, Groth A, Mueller S, Pfannkuche M, Verheyen F, Linder $\mathrm{R}$, et al. Oral anticoagulation use by patients with atrial fibrillation in Germany. Adherence to guidelines, causes of anticoagulation under-use and its clinical outcomes, based on claims-data of 183,448 patients. Thromb Haemost. 2012;107(6):1053-65.

9. Gage BF, Boechler M, Doggette AL, Fortune G, Flaker GC, Rich MW, et al. Adverse outcomes and predictors of underuse of antithrombotic therapy in medicare beneficiaries with chronic atrial fibrillation. Stroke J Cereb Circ. 2000;31(4):822-7.

10. De Caterina R, Husted S, Wallentin L, Andreotti F, Arnesen H, Bachmann F, et al. General mechanisms of coagulation and targets of anticoagulants (Section I). Position Paper of the ESC Working Group on Thrombosis-Task Force on Anticoagulants in Heart Disease. Thromb Haemost. 2013;109(4):569-79.

11. Camm AJ, Lip GY, De Caterina R, Savelieva I, Atar D, Hohnloser SH, et al. 2012 focused update of the ESC guidelines for the management of atrial fibrillation: an update of the 2010 ESC guidelines for the management of atrial fibrillation. Developed with the special contribution of the European Heart Rhythm Association. Eur Heart J. 2012;24(33):2719-47.

12. Skanes AC, Healey JS, Cairns JA, Dorian P, Gillis AM, McMurtry MS, et al. Focused 2012 update of the Canadian Cardiovascular Society atrial fibrillation guidelines: recommendations for stroke prevention and rate/rhythm control. Can J Cardiol. 2012;28(2):125-36.

13. January CT, Wann LS, Alpert JS, Calkins H, Cleveland JC, Cigarroa JE, et al. 2014 AHA/ACC/HRS guideline for the management of patients with atrial fibrillation: a report of the American College of Cardiology/American Heart Association Task Force on Practice Guidelines and the Heart Rhythm Society. J Am Coll Cardiol. Epub 28 Mar 2014. doi:10.1016/j.jacc.2014. 03.022

14. Furie KL, Goldstein LB, Albers GW, Khatri P, Neyens R, Turakhia MP, et al. Oral antithrombotic agents for the prevention 
of stroke in nonvalvular atrial fibrillation: a science advisory for healthcare professionals from the American Heart Association/ American Stroke Association. Stroke J Cereb Circ. 2012;43(12):3442-53.

15. Kearon C, Akl EA, Comerota AJ, Prandoni P, Bounameaux H, Goldhaber SZ, et al. Antithrombotic therapy for VTE disease: Antithrombotic Therapy and Prevention of Thrombosis, 9th ed: American College of Chest Physicians Evidence-Based Clinical Practice Guidelines. Chest. 2012;141(2 Suppl):e419S-94S.

16. Ruff CT, Giugliano RP, Braunwald E, Hoffman EB, Deenadayalu $\mathrm{N}$, Ezekowitz MD, et al. Comparison of the efficacy and safety of new oral anticoagulants with warfarin in patients with atrial fibrillation: a meta-analysis of randomised trials. Lancet. 2014;383(9921):955-62.

17. van der Hulle T, Kooiman J, den Exter PL, Dekkers OM, Klok FA, Huisman MV. Effectiveness and safety of novel oral anticoagulants compared with vitamin K-antagonists in the treatment of acute symptomatic venous thromboembolism: a systematic review and meta-analysis. J Thromb Haemost. 2014;12(2):320-8.

18. Zafar MU, Vorchheimer DA, Gaztanaga J, Velez M, Yadegar D, Moreno PR, et al. Antithrombotic effects of factor Xa inhibition with DU-176b: phase-I study of an oral, direct factor Xa inhibitor using an ex-vivo flow chamber. Thromb Haemost. 2007;98(4): 883-8.

19. Ogata K, Mendell-Harary J, Tachibana M, Masumoto H, Oguma T, Kojima M, et al. Clinical safety, tolerability, pharmacokinetics, and pharmacodynamics of the novel factor Xa inhibitor edoxaban in healthy volunteers. J Clin Pharmacol. 2010;50(7): 743-53.

20. Zahir H, Matsushima N, Halim AB, He L, Zhang G, Lee F, et al. Edoxaban administration following enoxaparin: a pharmacodynamic, pharmacokinetic, and tolerability assessment in human subjects. Thromb Haemost. 2012;108(1):166-75.

21. Matsushima N, Lee F, Sato T, Weiss D, Mendell J. Bioavailability and safety of the factor $\mathrm{Xa}$ inhibitor edoxaban and the effects of quinidine in healthy subjects. Clin Pharm Drug Dev. 2013;2(4):358-66.

22. Mendell J, Zahir H, Matsushima N, Noveck R, Lee F, Chen S, et al. Drug-drug interaction studies of cardiovascular drugs involving P-glycoprotein, an efflux transporter, on the pharmacokinetics of edoxaban, an oral factor Xa inhibitor. Am J Cardiovasc Drugs. 2013;13(5):331-42.

23. Mendell J, Chen S, He L, Parasrampuria D. The effect of rifampin on the PK and PD of edoxaban in healthy subjects. J Thromb Haemost. 2014;12(Suppl 1): 17.

24. Parasrampuria D, Matsushima N, Chen S, Wickremasingha P, Chatham N, He L, et al. Safety, tolerability and pharmacokinetics of edoxaban in end-stage renal disease subjects undergoing hemodialysis [abstract OC 79.1]. XXIV Congress of the International Society on Thrombosis and Haemostasis; 29 Jun-4 Jul 2013; Amsterdam.

25. Mendell J, Tachibana M, Shi M, Kunitada S. Effects of food on the pharmacokinetics of edoxaban, an oral direct factor Xa inhibitor, in healthy volunteers. J Clin Pharmacol. 2011;51(5):687-94.

26. Mendell J, Shi M. Safety, tolerability, pharmacokinetic (PK) and pharmacodynamic (PD) profiles of edoxaban in healthy postmenopausal or surgically sterile females, and healthy elderly males [abstract]. Eur Heart J; 2011;32 Suppl 1:461.

27. Masumoto H, Yoshigae Y, Watanabe K, Takakusa H, Okazaki O, Izumi T. In vitro metabolism of edoxaban and the enzymes involved in the oxidative metabolism of edoxaban [abstract]. AAPS J. 2010;12(S2):W4308.

28. Bathala MS, Masumoto H, Oguma T, He L, Lowrie C, Mendell J. Pharmacokinetics, biotransformation, and mass balance of edoxaban, a selective, direct factor xa inhibitor, in humans. Drug Metab Dispos. 2012;40(12):2250-5.
29. Mikkaichi T, Yoshigae Y, Masumoto H, Imaoka T, Rozehnal V, Fischer T, et al. Edoxaban transport via P-glycoprotein is a key factor for the drug's disposition. Drug Metab Dispos. 2014;42(4):520-8.

30. Giugliano RP, Ruff CT, Braunwald E, Murphy SA, Wiviott SD, Halperin JL, et al. Edoxaban versus warfarin in patients with atrial fibrillation. N Engl J Med. 2013;369(22):2093-104.

31. Mueck W, Kubitza D, Becka M. Co-administration of rivaroxaban with drugs that share its elimination pathways: pharmacokinetic effects in healthy subjects. $\mathrm{Br} \mathrm{J}$ Clin Pharmacol. 2013;76(3):455-66.

32. Mendell J, Lee F, Chen S, Worland V, Shi M, Samama MM. The effects of the antiplatelet agents, aspirin and naproxen, on pharmacokinetics and pharmacodynamics of the anticoagulant edoxaban, a direct factor $\mathrm{Xa}$ inhibitor. J Cardiovas Pharmacol. 2013;62(2):212-21.

33. Hokusai-VTE Investigators. Edoxaban versus warfarin for the treatment of symptomatic venous thromboembolism. N Engl J Med. 2013;369(15):1406-15.

34. Mendell J, Noveck RJ, Shi M. A randomized trial of the safety, pharmacokinetics and pharmacodynamics of edoxaban, an oral factor Xa inhibitor, following a switch from warfarin. Br J Clin Pharmacol. 2012;75(4):966-78.

35. Mendell J, Basavapathruni R, Swearingen D, Draves A, Zhang G, Morganroth J. A thorough electrocardiogram study of edoxaban, a novel factor Xa inhibitor. J Clin Pharmacol. 2011;51(8):1241-6.

36. Weitz JI, Connolly SJ, Patel I, Salazar D, Rohatagi S, Mendell J, et al. Randomised, parallel-group, multicentre, multinational phase 2 study comparing edoxaban, an oral factor Xa inhibitor, with warfarin for stroke prevention in patients with atrial fibrillation. Thromb Haemost. 2010;104(3):633-41.

37. Yamashita $\mathrm{T}$, Koretsune $\mathrm{Y}$, Yasaka $\mathrm{M}$, Inoue $\mathrm{H}$, Kawai $\mathrm{Y}$, Yamaguchi T, et al. Randomized, multicenter, warfarin-controlled phase II study of edoxaban in Japanese patients with nonvalvular atrial fibrillation. Circ J. 2012;76(8):1840-7.

38. Chung N, Jeon HK, Lien LM, Lai WT, Tse HF, Chung WS, et al. Safety of edoxaban, an oral factor Xa inhibitor, in Asian patients with non-valvular atrial fibrillation. Thromb Haemost. 2011;105(3):535-44.

39. Koretsune Y, Inoue H, Kawai Y. The oral factor Xa inhibitor DU$176 \mathrm{~b}$ in Japanese warfarin-naive patients with atrial fibrillation: results of two phase II open-label, dose-escalation studies [abstract]. 58th Annual Scientific Session of the American College of Cardiology. Orlando (FL); 2009. p. 1022-114.

40. Salazar DE, Mendell J, Kastrissios H, Green M, Carrothers TJ, Song S, et al. Modelling and simulation of edoxaban exposure and response relationships in patients with atrial fibrillation. Thromb Haemost. 2012;107(5):925-36.

41. Ruff CT, Giugliano RP, Antman EM, Crugnale SE, Bocanegra T, Mercuri M, et al. Evaluation of the novel factor Xa inhibitor edoxaban compared with warfarin in patients with atrial fibrillation: design and rationale for the Effective aNticoaGulation with factor xA next GEneration in Atrial Fibrillation-Thrombolysis In Myocardial Infarction study 48 (ENGAGE AF-TIMI 48). Am Heart J. 2010;160(4):635-41.

42. Falck-Ytter Y, Francis CW, Johanson NA, Curley C, Dahl OE, Schulman S, et al. Prevention of VTE in orthopedic surgery patients: Antithrombotic Therapy and Prevention of Thrombosis, 9th ed: American College of Chest Physicians Evidence-Based Clinical Practice Guidelines. Chest. 2012;141(2 Suppl):e278S$325 \mathrm{~S}$.

43. Raskob G, Cohen AT, Eriksson BI, Puskas D, Shi M, Bocanegra $\mathrm{T}$, et al. Oral direct factor Xa inhibition with edoxaban for thromboprophylaxis after elective total hip replacement: a randomised double-blind dose-response study. Thromb Res. 2010;104(3):642-9. 
44. Fuji T, Wang C-J, Fujita S. Safety and efficacy of edoxaban, an oral factor Xa inhibitor, for thromboprophylaxis after total hip arthroplasty in Japan and Taiwan. J Arthroplast. 2014. doi:10. 1016/j.arth.2014.05.029.

45. Fuji T, Fujita S, Tachibana S, Kawai Y. A dose-ranging study evaluating the oral factor Xa inhibitor edoxaban for the prevention of venous thromboembolism in patients undergoing total knee arthroplasty. J Thromb Haemost. 2010;8(11):2458-68.

46. Koretsune Y, Yamashita T, Yasaka M. Evaluation of edoxaban in patients with atrial fibrillation and severe renal impairment. Eur Heart J. 2013;34 Suppl 1. doi:10.1093/eurheartj/eht307.P520

47. Fuji T, Satoru F, Yasuyuki A, Shintaro T, Yohko K. Evaluation of edoxaban in Japanese patients with severe renal impairment undergoing lower-limb orthopedic surgery. XXIV Congress of the International Society on Thrombosis and Haemostasis; 29 Jun-4 Jul 2013; Amsterdam.

48. Raskob G, Buller H, Prins M, Segers A, Shi M, Schwocho L, et al. Edoxaban for the long-term treatment of venous thromboembolism: rationale and design of the Hokusai-venous thromboembolism study-methodological implications for clinical trials. J Thromb Haemost. 2013;11(7):1287-94.

49. Raskob GE, Buller H, Angchaisuksiri P, Oh D, Boda Z, Lyons $\mathrm{RL}$, et al. Edoxaban for long-term treatment of venous thromboembolism in cancer patients [332]. New Orleans: American Society of Hematology. Blood. 2013;122(21):211.

50. Fuji T, Wang C-J, Fujita S, Tachibana S, Kawai Y, Koretsune Y, et al. Edoxaban versus enoxaparin for thromboprophylaxis after total knee arthroplasty: the STARS E-3 trial [ICT abstract]. Pathophysiol Haemost Thromb. 2010;37 Suppl 1:OC297.

51. Fuji T, Fujita S, Tachibana S. Efficacy and safety of edoxaban versus enoxaparin for the prevention of venous thromboembolism following total hip arthroplasty: STARS J-V trial. American Society of Hematology Annual Meeting Abstracts; 2010. p. 3320.

52. Fuji T, Fujita S, Kawai Y, Nakamura M, Kimura T, Kiuchi Y, et al. Safety and efficacy of edoxaban in patients undergoing hip fracture surgery. Thromb Res. 2014;133(6):1016-22.

53. Kuroda Y, Hirayama C, Hotoda H, Nishikawa Y, Nishiwaki A. Postmarketing safety experience with edoxaban in Japan for thromboprophylaxis following major orthopedic surgery. Vasc Health Risk Manage. 2013;9:593-8.

54. Kaatz S, Kouides PA, Garcia DA, Spyropolous AC, Crowther M, Douketis JD, et al. Guidance on the emergent reversal of oral thrombin and factor Xa inhibitors. Am J Hematol. 2012;87(Suppl 1):S141-5.

55. Fukuda T, Honda Y, Kamisato C, Morishima Y, Shibano T. Reversal of anticoagulant effects of edoxaban, an oral, direct factor Xa inhibitor, with haemostatic agents. Thromb Haemost. 2012;107(2):253-9.

56. Lu G, DeGuzman FR, Hollenbach SJ, Karbarz MJ, Abe K, Lee G, et al. A specific antidote for reversal of anticoagulation by direct and indirect inhibitors of coagulation factor Xa. Nat Med. 2013;19(4):446-51.

57. Crowther M, Vandana M, Michael K, Genmin L, Conley PB, Stanley $\mathrm{H}$, et al. A phase 2 randomized, double-blind, placebocontrolled trial demonstrating reversal of rivaroxaban-induced anticoagulation in healthy subjects by andexanet alfa (PRT064445), an antidote for FXa inhibitors. New Orleans: ASH; 2013.

58. Bakhru S, Laulicht B, Jiang X, Chen L, Pan L. PER977: A synthetic small molecule which reverses over-dosage and bleeding by the new oral anticoagulants [abstract no. 18809]. Dallas: American Heart Association. Circulation. 2013;128(22 Suppl).

59. Laulicht B, Bakhru S, Jiang X, Chen L, Pan D, Grosso M, et al. Antidote for new oral anticoagulants: mechanism of action and binding specificity of PER977. ISTH: J Thromb Haemost; 2013.
60. Fuji T, Wang C-J, Fujita S. Edoxaban versus enoxaparin for thromboprophylaxis after total knee arthroplasty: the STARS E-3 trial [ICT abstract]. Pathophysiol Haemost Thromb; 2010. p. OC297.

61. Stambler BS. A new era of stroke prevention in atrial fibrillation: comparing a new generation of oral anticoagulants with warfarin. Int Arch Med. 2013;6(1):46.

62. Boehringer Ingelheim Pharmaceuticals I. Pradaxa $110 \mathrm{mg}$ hard capsules summary of product characteristics. 2013.

63. BMS/Pfizer. Eliquis $5 \mathrm{mg}$ summary of product characteristics. 2013.

64. Bayer. Xarelto $15 \mathrm{mg}$ summary of product characteristics. 2014.

65. Stampfuss J, Kubitza D, Becka M, Mueck W. The effect of food on the absorption and pharmacokinetics of rivaroxaban. Int J Clin Pharmacol Ther. 2013;51(7):549-61.

66. Patel MR, Mahaffey KW, Garg J, Pan G, Singer DE, Hacke W, et al. Rivaroxaban versus warfarin in nonvalvular atrial fibrillation. N Engl J Med. 2011;365(10):883-91.

67. Hori M, Matsumoto M, Tanahashi N, Momomura S, Uchiyama S, Goto S, et al. Rivaroxaban vs. warfarin in Japanese patients with atrial fibrillation-the J-ROCKET AF study. Circ J. 2012;76(9): 2104-11.

68. Granger CB, Alexander JH, McMurray JJ, Lopes RD, Hylek EM, Hanna M, et al. Apixaban versus warfarin in patients with atrial fibrillation. N Engl J Med. 2011;365(11):981-92.

69. Connolly SJ, Eikelboom J, Joyner C, Diener HC, Hart R, Golitsyn $\mathrm{S}$, et al. Apixaban in patients with atrial fibrillation. $\mathrm{N}$ Engl $\mathrm{J}$ Med. 2011;364(9):806-17.

70. Connolly SJ, Ezekowitz MD, Yusuf S, Eikelboom J, Oldgren J, Parekh A, et al. Dabigatran versus warfarin in patients with atrial fibrillation. N Engl J Med. 2009;361(12):1139-51.

71. Connolly SJ, Wallentin L, Ezekowitz MD, Eikelboom J, Oldgren J, Reilly PA, et al. The long-term multicenter observational study of dabigatran treatment in patients with atrial fibrillation (RELYABLE) study. Circulation. 2013;128(3):237-43.

72. EINSTEIN Investigators, Bauersachs R, Berkowitz SD, Brenner B, Buller HR, Decousus H, et al. Oral rivaroxaban for symptomatic venous thromboembolism. N Engl J Med. 2010;363(26): 2499-510.

73. EINSTEIN-PE Investigators, Buller HR, Prins MH, Lensin AW, Decousus $\mathrm{H}$, Jacobson BF, et al. Oral rivaroxaban for the treatment of symptomatic pulmonary embolism. N Engl J Med. 2012;366(14):1287-97.

74. Cohen AT, Spiro TE, Buller HR, Haskell L, Hu D, Hull R, et al. Rivaroxaban for thromboprophylaxis in acutely ill medical patients. N Engl J Med. 2013;368(6):513-23.

75. Mega JL, Braunwald E, Wiviott SD, Bassand JP, Bhatt DL, Bode $\mathrm{C}$, et al. Rivaroxaban in patients with a recent acute coronary syndrome. N Engl J Med. 2012;366(1):9-19.

76. Agnelli G, Buller HR, Cohen A, Curto M, Gallus AS, Johnson M, et al. Oral apixaban for the treatment of acute venous thromboembolism. N Engl J Med. 2013;369(9):799-808.

77. Agnelli G, Buller HR, Cohen A, Curto M, Gallus AS, Johnson M, et al. Apixaban for extended treatment of venous thromboembolism. N Engl J Med. 2013;368(8):699-708.

78. Alexander JH, Lopes RD, James S, Kilaru R, He Y, Mohan P, et al. Apixaban with antiplatelet therapy after acute coronary syndrome. N Engl J Med. 2011;365(8):699-708.

79. Goldhaber SZ, Leizorovicz A, Kakkar AK, Haas SK, Merli G, Knabb RM, et al. Apixaban versus enoxaparin for thromboprophylaxis in medically ill patients. N Engl J Med. 2011;365(23): 2167-77.

80. Schulman S, Kearon C, Kakkar AK, Mismetti P, Schellong S, Eriksson $\mathrm{H}$, et al. Dabigatran versus warfarin in the treatment of acute venous thromboembolism. N Engl J Med. 2009;361(24): 2342-52. 
81. Schulman S, Kakkar AK, Goldhaber SZ, Schellong S, Eriksson $\mathrm{H}$, Mismetti $\mathrm{P}$, et al. Treatment of acute venous thromboembolism with dabigatran or warfarin and pooled analysis. Circulation. 2014;129(7):764-72.

82. Schulman S, Kearon C, Kakkar AK, Schellong S, Eriksson H, Baanstra D, et al. Extended use of dabigatran, warfarin, or placebo in venous thromboembolism. N Engl J Med. 2013;368(8): 709-18.

83. Portola Pharmaceuticals. Acute medically ill VTE prevention with extended duration betrixaban study (The APEX Study) [ClinicalTrials.gov identifier NCT01583218]. US National Institutes of Health, ClinicalTrials.gov. http://clinicaltrial.gov/ct2/ show/study/NCT01583218. Accessed 24 Jan 2014

84. Eriksson BI, Borris LC, Friedman RJ, Haas S, Huisman MV, Kakkar AK, et al. Rivaroxaban versus enoxaparin for thromboprophylaxis after hip arthroplasty. N Engl J Med. 2008;358(26): 2765-75.

85. Kakkar AK, Brenner B, Dahl OE, Eriksson BI, Mouret P, Muntz $\mathrm{J}$, et al. Extended duration rivaroxaban versus short-term enoxaparin for the prevention of venous thromboembolism after total hip arthroplasty: a double-blind, randomised controlled trial. Lancet. 2008;372(9632):31-9.

86. Lassen MR, Ageno W, Borris LC, Lieberman JR, Rosencher N, Bandel TJ, et al. Rivaroxaban versus enoxaparin for thromboprophylaxis after total knee arthroplasty. $\mathrm{N}$ Engl $\mathrm{J}$ Med. 2008;358(26):2776-86.

87. Turpie AG, Lassen MR, Davidson BL, Bauer KA, Gent M, Kwong LM, et al. Rivaroxaban versus enoxaparin for thromboprophylaxis after total knee arthroplasty (RECORD4): a randomised trial. Lancet. 2009;373(9676):1673-80.
88. Lassen MR, Raskob GE, Gallus A, Pineo G, Chen D, Portman RJ. Apixaban or enoxaparin for thromboprophylaxis after knee replacement. N Engl J Med. 2009;361(6):594-604.

89. Lassen MR, Raskob GE, Gallus A, Pineo G, Chen D, Hornick P, et al. Apixaban versus enoxaparin for thromboprophylaxis after knee replacement (ADVANCE-2): a randomised double-blind trial. Lancet. 2010;375(9717):807-15.

90. Lassen MR, Gallus A, Raskob GE, Pineo G, Chen D, Ramirez LM, et al. Apixaban versus enoxaparin for thromboprophylaxis after hip replacement. N Engl J Med. 2010;363(26):2487-98.

91. Eriksson BI, Dahl OE, Rosencher N, Kurth AA, van Dijk CN, Frostick SP, et al. Dabigatran etexilate versus enoxaparin for prevention of venous thromboembolism after total hip replacement: a randomised, double-blind, non-inferiority trial. Lancet. 2007;370(9591):949-56.

92. Eriksson BI, Dahl OE, Huo MH, Kurth AA, Hantel S, Hermansson $\mathrm{K}$, et al. Oral dabigatran versus enoxaparin for thromboprophylaxis after primary total hip arthroplasty (RE-NOVATE II*). A randomised, double-blind, non-inferiority trial. Thromb Haemost. 2011;105(4):721-9.

93. Eriksson BI, Dahl OE, Rosencher N, Kurth AA, van Dijk CN, Frostick SP, et al. Oral dabigatran etexilate vs. subcutaneous enoxaparin for the prevention of venous thromboembolism after total knee replacement: the RE-MODEL randomized trial. J Thromb Haemost. 2007;5(11):2178-85.

94. RE-MOBILIZE Writing Committee, Ginsberg JS, Davidson BL, Comp PC, Francis CW, Friedman RJ, et al. Oral thrombin inhibitor dabigatran etexilate vs North American enoxaparin regimen for prevention of venous thromboembolism after knee arthroplasty surgery. J Arthroplasty. 2009;24(1):1-9. 